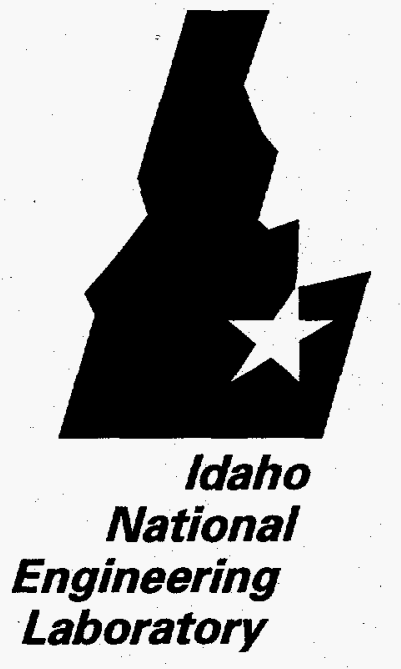

INEL-96/0036

H FIVED

January 1996

FER 231998

OSTI

Actinide Extraction From ICPP

Sodium Bearing Waste With

0.75 M DHDECMP/TBP In Isopar $L^{\circledR}$

R. S. Herbst

K. N. Brewer

T. G. Garn

J. D. Law

A. M. Rodriguez

R. T. Tillotson

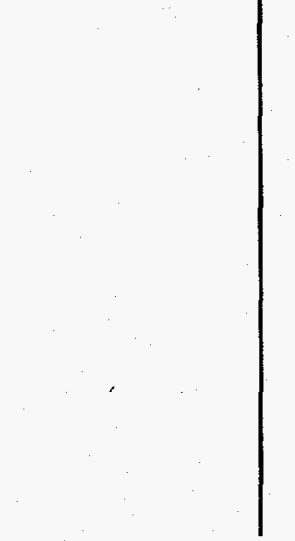

Zulockheed
Idaho Technologies company 


\title{
ACTINIDE EXTRACTION FROM ICPP SODIUM BEARING WASTE WITH 0.75 M DHDECMP/TBP IN ISOPAR $\mathrm{L}^{\circledR}$
}

\author{
R. S. Herbst \\ K. N. Brewer \\ T. G. Garn \\ J. D. Law \\ A. M. Rodriguez \\ R. T. Tillotson
}

January 1996

Lockheed Idaho Technologies Co.

Idaho Chemical Processing Plant

Prepared for the

U.S. Department of Energy

Assistant Secretary for Environmental Management Under DOE Idaho Operations Office Contract DE-AC07-94ID13223

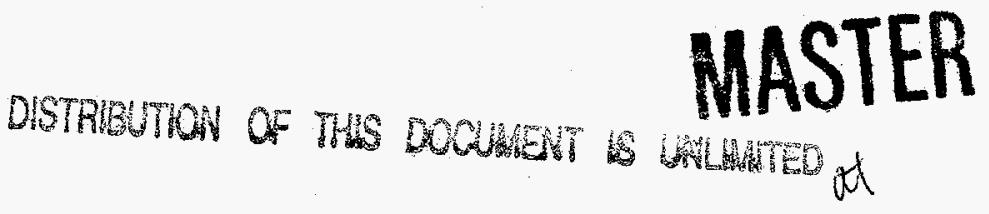




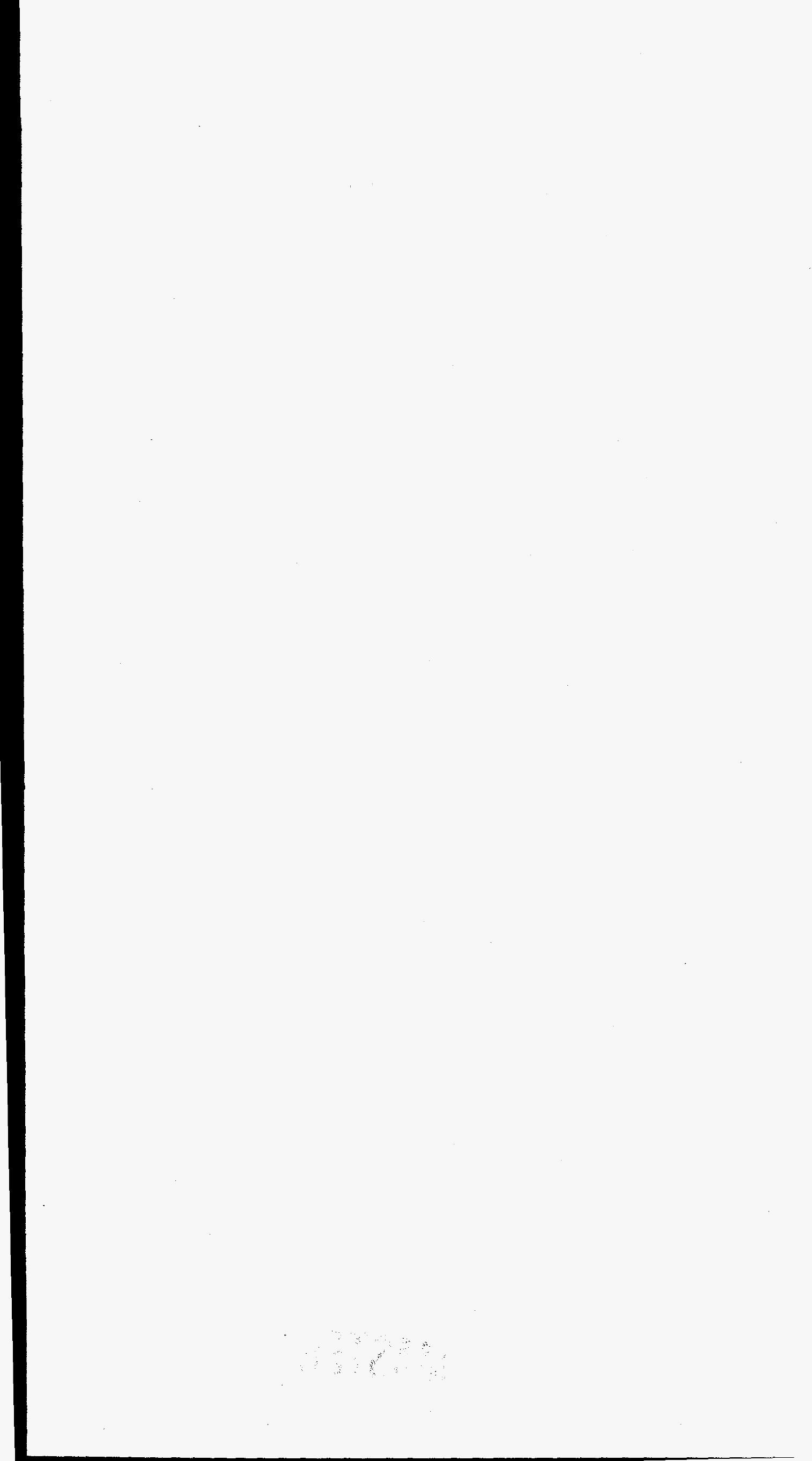




\section{ACKNOWLEDGEMENTS}

The authors gratefully acknowledge the support of the Analytical Chemistry Department at the Idaho Chemical Processing Plant. T. J. Tranter, I. D. Goodwin, and B. J. Storms of the Radiochemical Analysis Group efficiently expedited the many radionuclide analyses required to support this work. Without the support of these individuals, this study would not have been possible.

\section{DISCLAIMER}

This report was prepared as an account of work sponsored by an agency of the United States Government. Neither the United States Government nor any agency thereof, nor any of their employees, makes any warranty, express or implied, or assumes any legal liability or responsibility for the accuracy, completeness, or usefulness of any information, apparatus, product, or process disclosed, or represents that its use would not infringe privately owned rights. Reference herein to any specific commercial product, process, or service by trade name, trademark, manufacturer, or otherwise does not necessarily constitute or imply its endorsement, recommendation, or favoring by the United States Government or any agency thereof. The views and opinions of authors expressed herein do not necessarily state or reflect those of the United States Government or any agency thereof. 


\begin{abstract}
Recent process development efforts at the Idaho Chemical Processing Plant include examination of solvent extraction technologies for actinide partitioning from sodium bearing waste (SBW) solutions. The use of $0.75 \mathrm{M}$ dihexyl-N, N-diethylcarbamoylmethylphosphonate (DHDECMP or simply CMP) and $1.0 \mathrm{M}$ tri-n-butyl phosphate (TBP) diluted in Isopar ${ }^{\circledR}$ was explored for actinide removal from simulated SBW solutions. Experimental evaluations included batch contacts in radiotracer tests with simulated sodium bearing waste solution to measure the extraction and recovery efficiency of the organic solvent. The radioactive isotopes utilized for this study included Pu-238, Pu-239, Am-241, U-233, Np-239, Zr-95, Tc-99m, and Hg-203. Extraction contacts of the organic solvent with the traced SBW simulant, strip (backextraction) contacts of the loaded organic solvent with either a 1-hydroxyethane-1, 1diphosphonic acid (HEDPA) in nitric acid solution or an oxalic acid in nitric acid solution, and solvent wash contacts with sodium carbonate were performed. The study demonstrated the affinity and selectivity of the organic solvent for the actinides over the inert elemental constituents of the SBW simulant with extraction distributions ranging from $\mathrm{D}_{\mathrm{Am}} \sim 23$ to $\mathrm{D}_{\mathrm{Pu}} \sim$ 1400. Mercury and zirconium were the predominate inert matrix components extracted, with distributions of $\mathrm{D}_{\mathrm{Hg}} \sim 10$ to 20 and $\mathrm{D}_{\mathrm{Zr}} \sim 1$. A solution of $0.04 \underline{\mathrm{M}}$ HEDPA in dilute nitric acid was the most effective reagent identified for back-extraction of the actinides and Zr. Mercury was most effectively re-extracted from the solvent with a nitric acid solution greater than $\sim 5 \underline{\mathrm{M}}$ $\mathrm{HNO}_{3}$. Based on the results of this study, a process flowsheet was recommended for continuous, countercurrent testing in the ICPP centrifugal contactor mockup using the DHDECMP organic solvent and the SBW simulant.
\end{abstract}



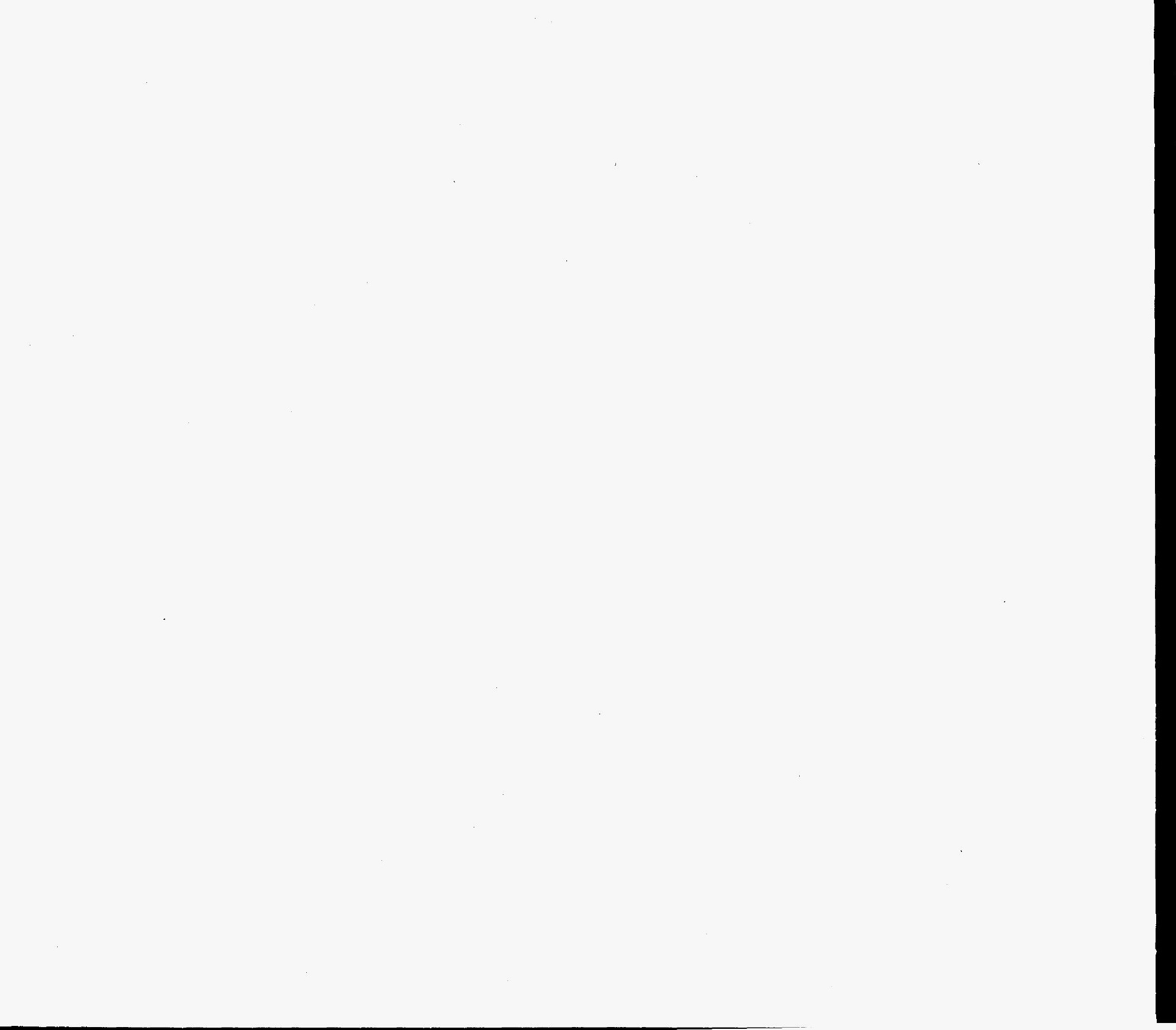

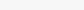




\section{TABLE OF CONTENTS}

ACKNOWLEDGEMENTS $\ldots \ldots \ldots \ldots \ldots \ldots \ldots \ldots \ldots \ldots \ldots \ldots \ldots \ldots \ldots$ iii

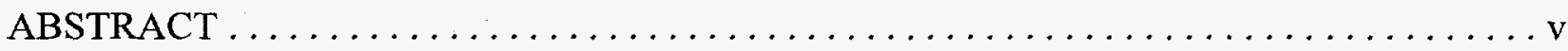

LIST OF TABLES $\ldots \ldots \ldots \ldots \ldots \ldots \ldots \ldots \ldots \ldots \ldots \ldots \ldots \ldots \ldots \ldots \ldots$

LIST OF FIGURES $\ldots \ldots \ldots \ldots \ldots \ldots \ldots \ldots \ldots \ldots \ldots \ldots \ldots \ldots \ldots \ldots \ldots$

INTRODUCTION $\ldots \ldots \ldots \ldots \ldots \ldots \ldots \ldots \ldots \ldots \ldots \ldots \ldots \ldots \ldots \ldots \ldots \ldots$

PURPOSE AND SCOPE $\ldots \ldots \ldots \ldots \ldots \ldots \ldots \ldots \ldots \ldots \ldots \ldots \ldots \ldots \ldots \ldots$

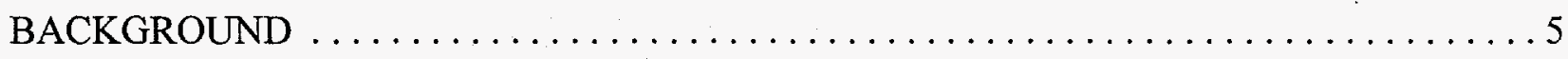

History of DHDECMP Solvent Extraction Research $\ldots \ldots \ldots \ldots \ldots \ldots \ldots \ldots$

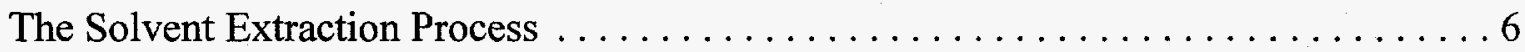

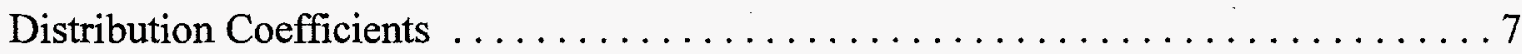

RESULTS AND DISCUSSION $\ldots \ldots \ldots \ldots \ldots \ldots \ldots \ldots \ldots \ldots \ldots \ldots \ldots \ldots \ldots \ldots$

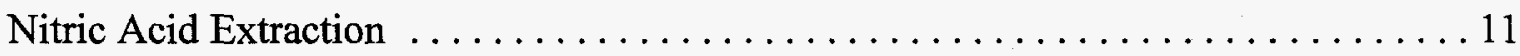

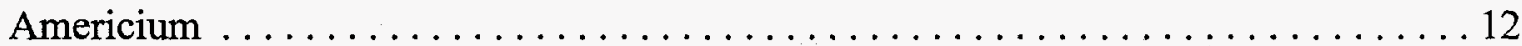

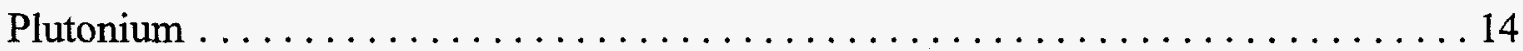

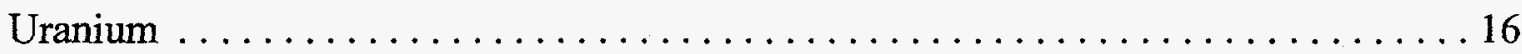

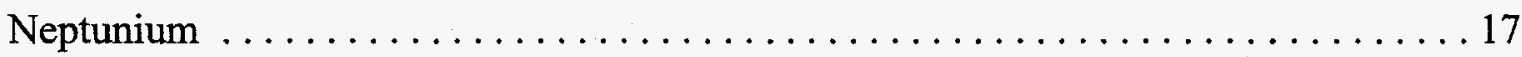

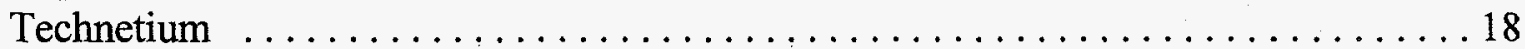

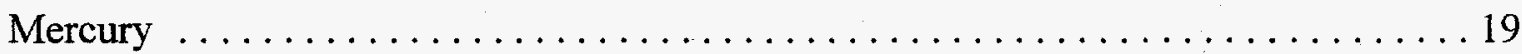

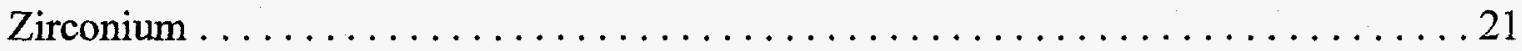

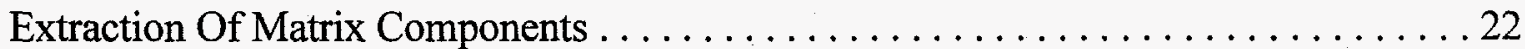

Proposed Flowsheet For The Treatment Of SBW $\ldots \ldots \ldots \ldots \ldots \ldots \ldots \ldots \ldots$

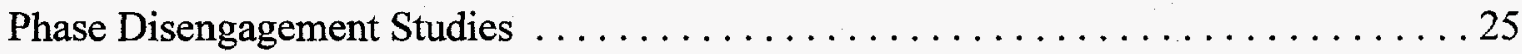

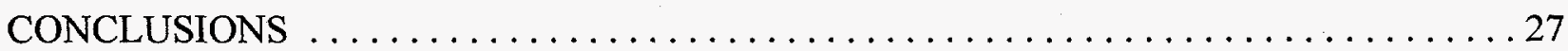

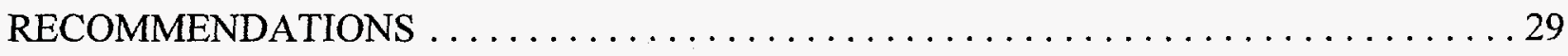

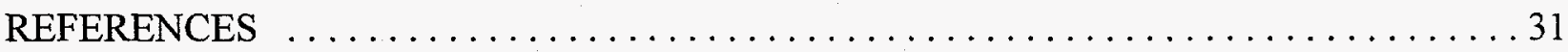

APPENDIX A:

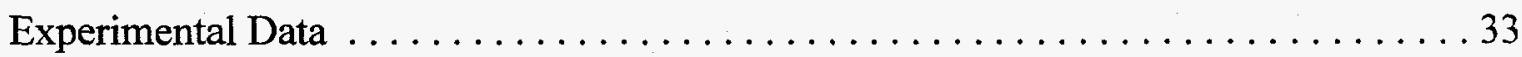




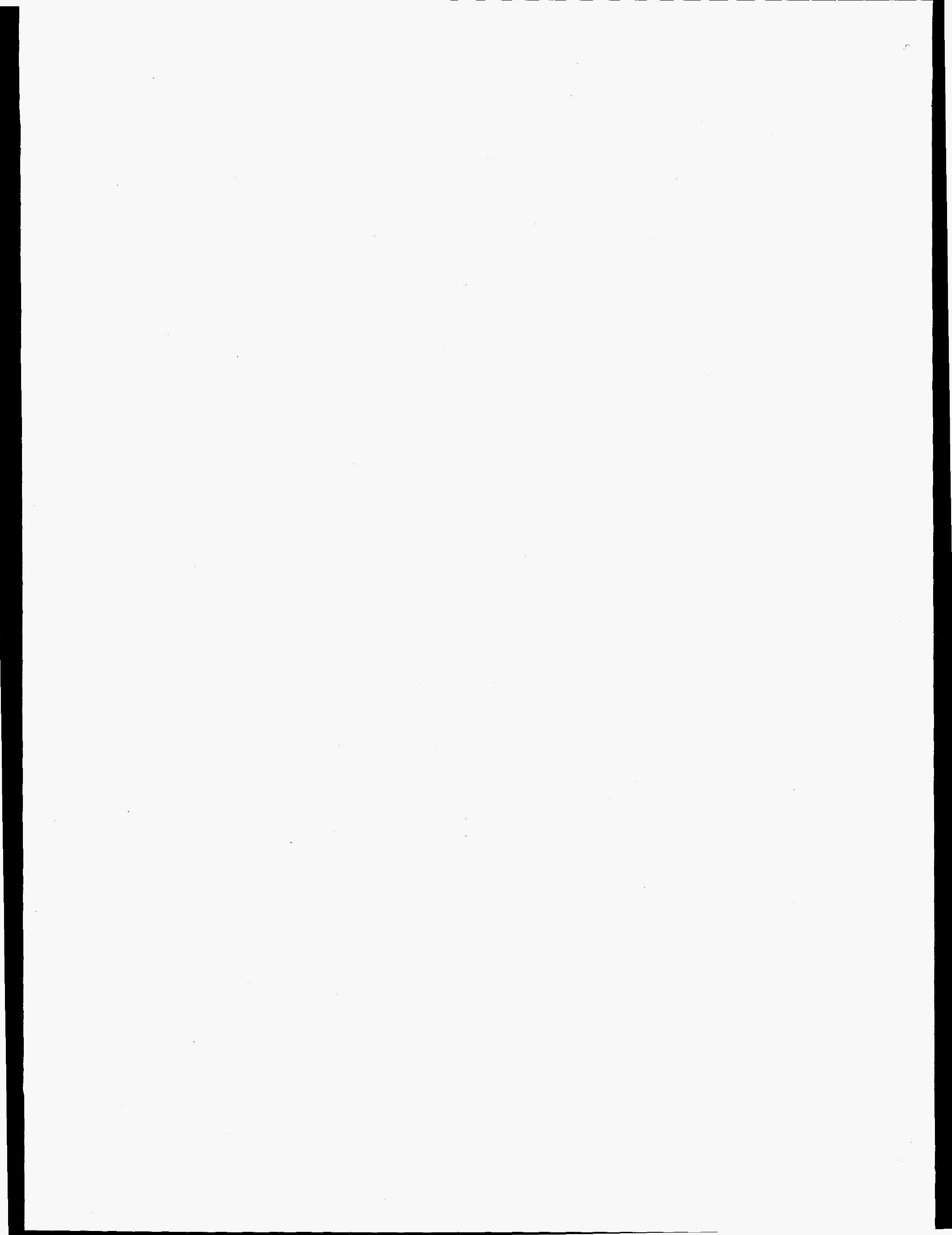




\section{LIST OF TABLES}

Table 1. Molar concentrations of selected constituents in simulated and actual SBW ......9

Table 2. Americium distribution coefficients for extraction and for various strip solutions $\ldots 13$

Table 3. Plutonium distribution coefficients with SBW simulant and various strip solutions . 15

Table 4. Uranium distribution coefficients with SBW simulant and various strip solutions $\ldots 16$

Table 5. Neptunium distribution coefficients with SBW simulant and various strip

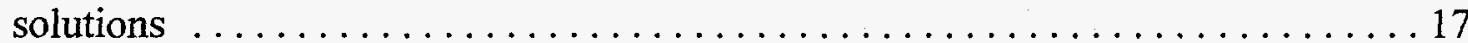

Table 6. Technetium distribution coefficients with simulated SBW and various strip

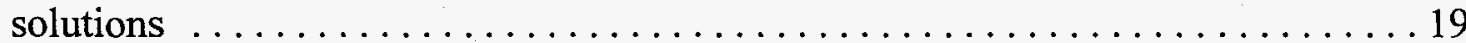

Table 7. Mercury distribution coefficients with simulated SBW and various strip solutions .. 21

Table 8. Zirconium distribution coefficients with simulated SBW and various strip

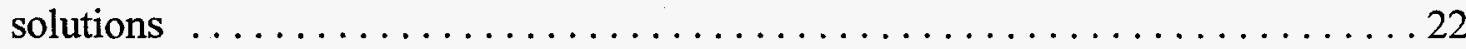

Table 9. Extraction distribution coefficients for non-radioactive components . . . . . . . 22

Table 10. Dispersion numbers from extraction, strip, wash, and re-acidification contacts $\ldots .25$

\section{LIST OF FIGURES}

Figure 1. General batch contacting test procedure $\ldots \ldots \ldots \ldots \ldots \ldots \ldots \ldots \ldots \ldots$

Figure 2. Equilibrium organic vs. aqueous acid concentrations $\ldots \ldots \ldots \ldots \ldots \ldots \ldots \ldots$

Figure 3. Americium distribution coefficients as a function of equilibrium

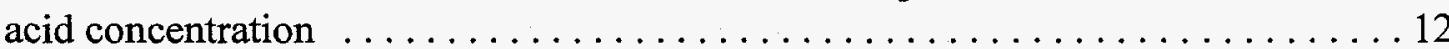

Figure 4. Plutonium distribution coefficients as a function of equilibrium acid concentration .................................... 14

Figure 5. Mercury distribution coefficients as a function of equilibrium acid concentration . . 20

Figure 6. Proposed flowsheet for the treatment of SBW with $0.75 \underline{\mathrm{M}}$ DHDECMP/1.4 $\mathrm{M}$ TBP

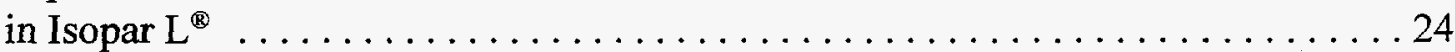


.
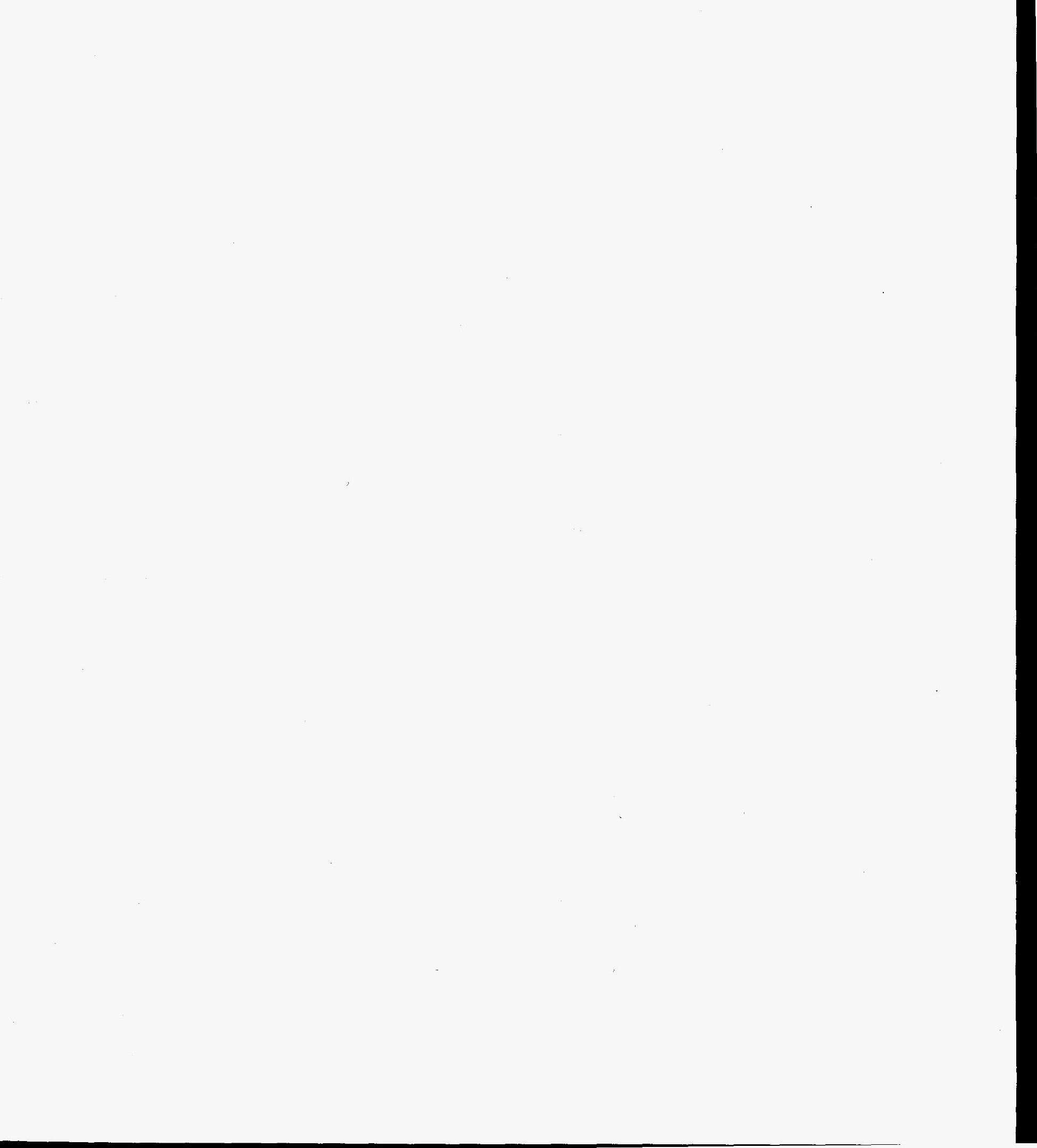


\section{INTRODUCTION}

The nuclear age in the United States has evolved into a complicated governmental infrastructure that supports everything from the mining and processing of uranium, to the production and reprocessing of nuclear fuels for test reactors. Many of the government sites which support these activities are currently involved in the remediation of their radioactively contaminated environments, decontamination and decommissioning of facilities, and in finding treatment alternatives for the stockpiles of spent nuclear reactor fuels and radioactive wastes in preparation for final disposal.

The Idaho Chemical Processing Plant (ICPP), located at the Idaho National Engineering Laboratory (INEL), supported national interests from 1954 to 1992 by reprocessing spent nuclear fuel to recover fissionable uranium. The mission of the ICPP has since changed from fuel reprocessing and currently includes development of economically suitable treatment alternatives in preparation for ultimate disposal of the radioactive wastes previously generated during decontamination and reprocessing activities.

The reprocessing activities at the ICPP generated significant quantities of radioactive liquid wastes, most of which have been solidified at $500^{\circ} \mathrm{C}$ in a fluidized-bed calciner to form a stable free-flowing granular waste form called calcine. Approximately $3800 \mathrm{~m}^{3}$ of calcine are currently in interim storage in six stainless steel bin sets placed within concrete vaults in near-surface locations. There are several different types of calcine composed of zirconia calcine, zirconia/sodium calcine, alumina calcine, and calcine from the last production campaign of the New Waste Calcining Facility completed in 1994 . The average zirconium concentration in a typical zirconia calcine can be as high as $20 \mathrm{wt} \%$, while the aluminum concentration in alumina calcines can be as high as $48 \mathrm{wt} \%$ [1]. The high aluminum and zirconium concentrations result from the dissolution of the cladding matrix of the spent nuclear fuel rods. Ultimately, the calcine wastes will be treated and prepared for permanent dispositioning.

Currently 6.8 million liters of radioactive liquid waste are temporarily stored in underground storage tanks at the ICPP. This secondary liquid waste was generated from equipment decontamination and solvent wash activities during numerous fuel reprocessing campaigns. Referred to as sodium bearing waste (SBW) because of its high sodium content, the SBW has traditionally been blended with reprocessing raffinates or non-radioactive aluminum nitrate and calcined. Dilution of SBW is required prior to calcination since the high sodium contentration results in bed agglomeration during operation of the fluidized bed calciner. The inventory of reprocessing raffinates available for blending with SBW was depleted as of November 1993. Direct calcination of the remaining SBW inventory by blending with aluminum nitrate would produce substantial quantities of solid calcine and require building additional calcine storage facilities. Calcination is considered interim storage since the solid must ultimately be placed in a form acceptable for permanent disposal. Alternative technologies to dilution and calcination are being evaluated in an effort to define an econmically feasible treatment option for SBW dispositioning. 


\section{PURPOSE AND SCOPE}

A panel of internationally renowned separations experts from the nuclear industry was assembled in early 1993 to facilitate the evaluation and selection of potential processing technologies applicable to treatment of ICPP nuclear wastes. Several solvent extraction technologies were identified as the most feasible actinide partitioning options for the treatment of ICPP wastes [2]. A subsequent Systems Engineering analysis indicated a phased waste treatment approach based on radionuclide partitioning as the economically preferred option for treatment of HLW at the ICPP [3]. In support of these recommendations, continued efforts have been devoted to defining appropriate solvent extraction based process flowsheets for actinide removal.

The purpose of this research was to evaluate the removal of actinides from SBW with dihexyl-N,N-diethylcarbamoylmethylphosphonate (DHDECMP) as the extractant. The composition of the extraction solvent was chosen to be $0.75 \underline{\mathrm{M}}$ DHDECMP and $1.0 \underline{\mathrm{M}} \mathrm{TBP}$ diluted in Isopar $\mathrm{L}^{\circledR}$ (a branched chain paraffinic hydrocarbon) based on literature sources and previous research at the ICPP. This solvent was evaluated for the removal of actinides from the bulk components of SBW in order to achieve an NRC Class A LLW classification. Separation and vitrification of the long-lived radionuclides and fission products from the inert constituents of the waste would result in a reduced amount of high-level waste requiring disposal in a deep geological repository, and a larger volume of Class A LLW, which could be grouted and stored on-site in above ground retrievable storage.

The scope of this study was limited to the use of batch contacts to measure equilibrium distribution coefficients and determine process characteristics of the solvent. Using this methodology, extraction, scrubbing, stripping, and solvent wash characteristics of the DHDECMP solvent were evaluated. This information was used to postulate a potential countercurrent flowsheet for testing in continuous mode with SBW simulant. This flowsheet was subsequently tested in the Centrifugal Contactor Pilot Plant with simulated sodium bearing waste using non-radioactive neodymium as a surrogate for americium. 

.

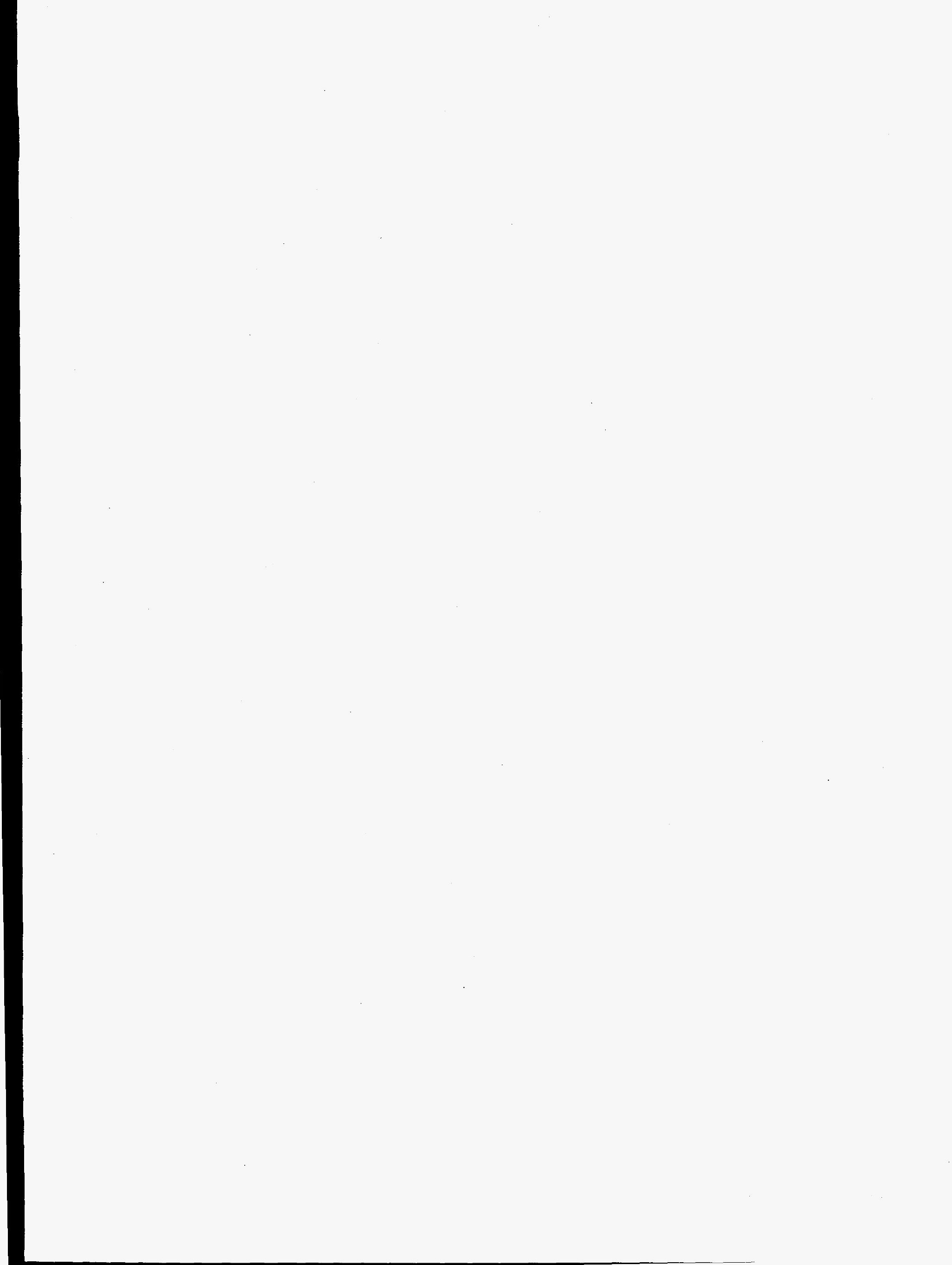




\section{BACKGROUND}

\section{History of DHDECMP Solvent Extraction Research}

T. H. Sidall first synthesized bidentate organophosphorus extractants in the 1960's. DHDECMP was chosen as a potential extractant because of its chemical similarity to tributyl phosphate (TBP), a monodentate extractant [4]. The TBP in n-dodecane has been extensively used in nuclear fuel reprocessing in the PUREX process for the recovery of fissionable uranium and plutonium. The use of DHDECMP was first studied at the ICPP in 1975 for the removal of actinides from first-cycle reprocessing raffinates. These early tests culminated with the experimental verification of the extraction process on actual reprocessing wastes and coprocessing raffinates $[5,6,7]$. The tests on the reprocessing wastes were performed with a mixture of 30 vol.\% DHDECMP and 70 vol.\% diisopropyl benzene (DIPB). The tests on the ICPP co-processing raffinates were performed with a mixture of 20 vol. $\%$ DHDECMP, 53 vol.\% decalin and 27 vol.\% DIPB. Both tests accomplished a 99.99\% extraction of the actinides and verified the applicability of the DHDECMP/aromatic diluent extraction system for actinide extraction $[6,7]$. Unfortunately, in today's regulatory environment the use of an aromatic diluent such as DIPB, potentially an explosion hazard from the possible nitration of the benzene ring, is not recommended for use in acidic and radiolytic conditions.

The organic solution was composed of $0.75 \mathrm{M}$ DHDECMP/ 1.0 $\mathrm{M}$ TBP diluted in Isopar $\mathrm{L}^{\circledR}$. Isopar $\mathrm{L}^{\circledR}$ (EXXON Chemical Co.) is the brand name of synthetically produced isoparaffinic solvents with an average carbon chain length of 12 carbons. An aliphatic diluent such as Isopar $\mathrm{L}^{\circledR}$ is typically acceptable from the standpoint of radiolytic and hydrolytic stability. TBP is added to the solvent as a phase modifier to enhance the hydrodynamic properties of the solution by increasing the solubility of extracted metal complexes formed with the DHDECMP and eliminate formation of a second organic phase. Although DHDECMP is a liquid, the viscosity and density of the undiluted material is significantly reduced by dilution, making the solvent better suited for a liquid-liquid extraction process.

The initial composition of the organic solvent utilized for this study was chosen based on previous research performed at Los Alamos National Laboratory and Pacific Northwest Laboratory with the DHDECMP organic solvent $[8,9]$. The Los Alamos study was performed with two different solvent compositions: $0.75 \underline{\mathrm{M}}$ DHDECMP and $1.0 \mathrm{M}$ TBP in Isopar $\mathrm{H}^{\circledR}$ and $0.75 \underline{\mathrm{M}}$ DHDECMP and 1.0 $\mathrm{M}$ TBP in tetrachloroethylene (TCE). The solvent compositions used in the Pacific Northwest Laboratory study were $0.75 \underline{\mathrm{M}}$ DHDECMP and $1.0 \mathrm{M}$ TBP in Isopar $\mathrm{M}^{\circledast}$ and $0.75 \underline{\mathrm{M}} \mathrm{DHDECMP}, 1.0 \underline{\mathrm{M}} \mathrm{TBP}$ in normal paraffinic hydrocarbons (NPH) [8,9].

The Los Alamos study was performed as a comparison between DHDECMP and CMPO to remove actinides from nitric acid streams. The results consistently found DHDECMP to have lower actinide extraction distribution coefficients than CMPO, but large enough to effect a complete actinide separation. Distribution coefficients were low enough to back-extract the actinides with low concentration nitric acid solutions without adverse physical problems [8]. 
The Pacific Northwest Laboratory study measured the distribution coefficients of uranium, plutonium and americium as a function of aqueous nitrate concentration in an effort to develop a potential flowsheet for the processing of wastes at the Hanford site. The study found the metal and acid loaded organic solvent had a tendency to form a second organic phase and precipitates. The precipitation was attributed to zirconium extracted from the liquid wastes. Third phase formation was prevalent at nitric acid concentrations above $2.0 \underline{\mathrm{M}} \mathrm{HNO}_{3}$ and attributed to acid extraction by the organic solvent. The study concluded that a potential flowsheet for the extraction of the actinides with DHDECMP was feasible and suggested that the actinides may be stripped by simply utilizing a low concentration acid solution [9].

The mechanism by which DHDECMP selectively removes trivalent, tetravalent, and hexavalent radionuclides from aqueous acidic solutions is based on the ability to satisfy the neutralized extracted species coordination sites. The coordination sites of a trivalent ion, such as $\mathrm{Am}^{+3}$, are satisfied by the electron density of the oxygens of three DHDECMP molecules, while three nitrate ions $\left(\mathrm{NO}_{3}{ }^{-}\right)$in solution, neutralize the +3 charge of the extracted ion species [4]. Thus, americium is extracted as a neutral species according to the following reaction:

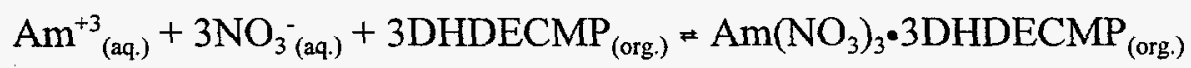

The extraction mechanisms of higher valence actinides are similar to that of americium and depend on the extractant and aqueous nitrate ion concentration [4]. DHDECMP has the greatest affinity for actinides in the +4 valence state (typically $\mathrm{Pu}$ ), followed by +6 ( $\mathrm{U}$ and $\mathrm{Pu}$ ) valence, the +3 valence $(\mathrm{Am})$, and being least selective for the +5 valence (Np) state.

Mercury is reportedly extracted by DHDECMP, and is not readily back-extracted from the organic with prescribed stripping agents such as dilute nitric acid. The DHDECMP/DIPB flowsheet developed by Maxey, et al., recommended the removal of mercury with $0.9 \underline{\mathrm{M}}$ potassium cyanide, followed by the electrolytic separation of mercury in order to recycle the aqueous cyanide stream [7]. Suggested methods for the removal of mercury from the organic solvent included complexants, aqueous reductants, electrolytic methods and solid sorbents [7, 10]. An aqueous solution of $0.1 \mathrm{M}$ potassium cyanide and $0.5 \underline{\mathrm{M}}$ sodium carbonate removed more than $99 \%$ of the mercury from the solvent with no adverse effects on the extraction capabilities of CMP [10]. A recovery system utilizing potassium cyanide is not recommended in today's regulatory environment. Due to the high mercury concentrations in the SBW, an adequate mercury recovery system will be necesary if a CMP process is to be implemented.

\section{The Solvent Extraction Process}

Solvent extraction systems have been widely applied in nuclear fuel reprocessing. Solvent extraction involves the mass transfer of a solute between an aqueous solution and an immiscible organic solvent. Extracted species are typically removed from the organic phase by contact with a different aqueous solution; a process referred to as "stripping" or "back-extraction" 
of the solute into an aqueous solution. The phase transfer of extracted species may sometimes be complicated by precipitation of insoluble species of the extracted components. Precipitates may be visually evident at the interface of the aqueous and organic phases, or settled on the bottom of the test container. In certain instances, when not visually evident, precipitate formation may be deduced when material balances do not close to within $\pm 10 \%$.

Solvent extraction systems require thorough mixing and efficient phase disengagement of the two immiscible phases to facilitate the mass transfer of the extractable species. In the absence of kinetic limitations, agitation ensures the solute concentration equilibrates between the two phases. The distribution of the solute between the two phases depends on the solubility of the extracted complex in each phase and the affinity of the extractant for the solute of interest. The extraction and stripping of the solute can be affected by the complexing strength of the organic solvent and the composition of the aqueous phase. For example, actinides have lower distribution coefficients in the DHDECMP organic solvent at lower nitric acid concentrations than at higher concentrations. Efficient phase disengagement is required to ensure the two immiscible liquids separate fast enough to be amenable for use with countercurrent process equipment.

Pulsed extraction columns have traditionally been utilized at the ICPP for the first-cycle uranium extraction process $[5,11]$. Extraction columns, although a mature technology, suffer some drawbacks since they are typically at least 20 feet tall and require rather large solvent inventories due to equipment volume. Furthermore, extraction columns often require at least twenty-four hours of operation prior to achieving steady state conditions. Centrifugal contactors, developed at Argonne National Laboratory (ANL) [12] and Oak Ridge National Laboratory (ORNL), are available as an alternative to extraction columns.

\section{Distribution Coefficients}

The efficiency of the solvent extraction system is often measured by determining equilibrium distribution coefficients for the extracted species of interest. The distribution coefficient is defined as the ratio of the concentration of a species in the organic phase, $[x]_{\text {org }}$ to the concentration of the species in the aqueous phase, $[\mathrm{x}]_{\text {aq. }}$, at equilibrium:

$$
\mathrm{D}_{\mathrm{x}}=\frac{[\mathrm{x}]_{\mathrm{org}}}{[\mathrm{x}]_{\mathrm{aq}}}
$$

A distribution coefficient greater than one is required for efficient extraction and distributions less than one are required for efficient stripping (back-extraction) of the extracted 
species. Distribution coefficients can be converted into percent extraction according to the equation:

$$
\% \text { Extraction }=\frac{D_{x}}{1+D_{x}} \times 100 \%
$$

Percent extraction of a species is a useful quantity since it is a direct description of the amount of species extracted in a given batch contact.

In instances where high concentrations of nitrate are present in the feed solution, salting effects of the nitrate drive the extraction of the species and often substantially enhance the distribution coefficients (see, for example, equation 1). Furthermore, distribution coefficients may be decreased by masking, or complexing, extractable species to prevent their extraction. For example, zirconium may be complexed with fluoride to preclude its extraction. Organic degradation products, caused by hydrolytic or radiolytic breakdown, can also decrease the extraction efficiency of organic solvent due to the formation of very stable metal complexes. A technique often used to remove degradation products is to wash the organic solvent with sodium carbonate $[5,6,13]$. 


\section{EXPERIMENTAL}

A simulated SBW solution was prepared to represent the average concentrations of the non-radioactive constituents in the actual waste. The composition of both simulated and actual SBW are found in Table 1. The simulant was utilized as the feed solution in most batch tests.

The tests included three pre-equilibration contacts, three extraction contacts, and several strip contacts with various stripping reagents. A general experimental flowsheet is shown in Figure 1. The measurement of distribution coefficients were facilitated by performing batch tests with SBW simulant spiked with a radioactive tracer.

Pre-equilibrations with the SBW simulant were performed in order to load the organic solvent with the extractable, inert constituents. The concentrations of the extractable, inert species approach equilibrium during the pre-equilibration steps. This procedure ensures that the radioactive tracer is the principle component partitioned between phases in the extraction contacts. After the extraction contacts, the loaded organic solvent was contacted with the appropriate strip solution.

Table 1. Molar concentrations of selected constituents in simulated and actual SBW.

\begin{tabular}{||l|c|c||l|c|c||}
\hline \multicolumn{1}{|c|}{ Element } & $\begin{array}{c}\text { Simulated } \\
\text { SBW }\end{array}$ & $\begin{array}{c}\text { Actual } \\
\text { SBW }\end{array}$ & Element & $\begin{array}{c}\text { Simulated } \\
\text { SBW }\end{array}$ & $\begin{array}{c}\text { Actual } \\
\text { SBW }\end{array}$ \\
\hline Acid & 1.4 & 1.4 & Manganese & $1.4 \mathrm{E}-02$ & $1.3 \mathrm{E}-02$ \\
\hline Aluminum & $6.5 \mathrm{E}-01$ & $5.6 \mathrm{E}-01$ & Mercury & $2.9 \mathrm{E}-03$ & $2.0 \mathrm{E}-03$ \\
\hline Boron & $1.7 \mathrm{E}-02$ & $1.4 \mathrm{E}-02$ & Molybdenum & $1.5 \mathrm{E}-03$ & $1.0 \mathrm{E}-03$ \\
\hline Cadmium & $2.3 \mathrm{E}-03$ & $1.9 \mathrm{E}-02$ & Nickel & $2.2 \mathrm{E}-03$ & $2.0 \mathrm{E}-03$ \\
\hline Calcium & $3.9 \mathrm{E}-02$ & $4.4 \mathrm{E}-02$ & Nitrate & 4.5 & 4.3 \\
\hline Chloride & $3.5 \mathrm{E}-02$ & $2.7 \mathrm{E}-02$ & Phosphate & $9.2 \mathrm{E}-03$ & $1.0 \mathrm{E}-02$ \\
\hline Chromium & $6.5 \mathrm{E}-03$ & $6.0 \mathrm{E}-03$ & Potassium & $1.4 \mathrm{E}-01$ & $1.5 \mathrm{E}-01$ \\
\hline Fluoride & $9.7 \mathrm{E}-02$ & $7.0 \mathrm{E}-02$ & Sodium & 1.3 & 1.3 \\
\hline Iron & $3.1 \mathrm{E}-02$ & $2.4 \mathrm{E}-02$ & Sulfate & $3.9 \mathrm{E}-02$ & $3.5 \mathrm{E}-02$ \\
\hline Lead & $1.1 \mathrm{E}-03$ & $1.0 \mathrm{E}-03$ & Zirconium & $1.0 \mathrm{E}-03$ & $3.0 \mathrm{E}-03$ \\
\hline
\end{tabular}


Figure 1. General batch contacting test procedure.

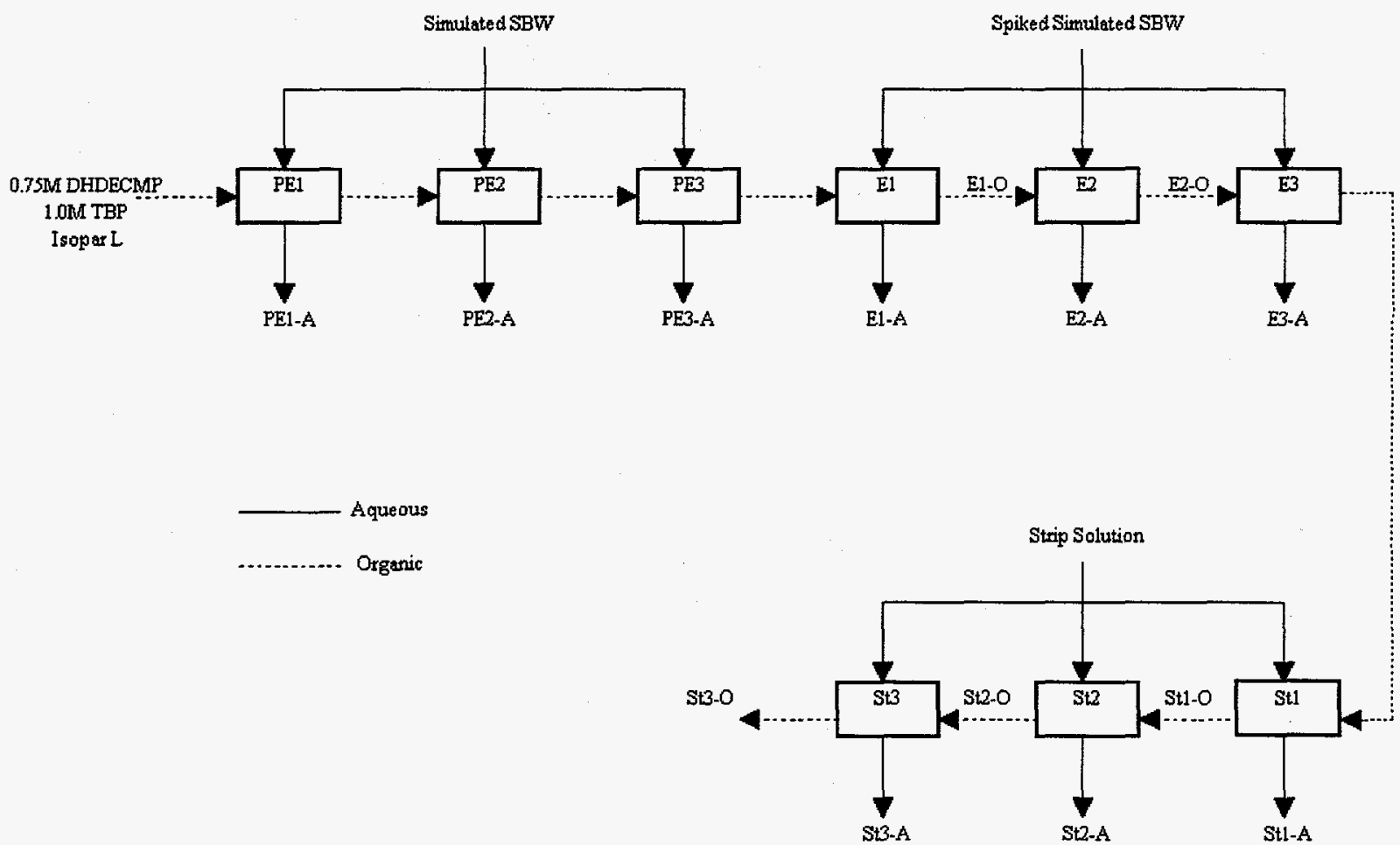

Analytical samples from the radiotracer tests were prepared according to the type of radioactive decay of the tracer. The alpha/beta emitting samples were prepared for liquid scintillation on a Beckman LS6000 by mixing a $1.0 \mathrm{~mL}$ aliquot of the appropriate sample with SCINTIVERSE II liquid scintillation cocktail in a 5 dram scintillation vial. The samples emitting gamma activity were prepared for $\gamma$-scan analysis on a gamma spectrometer. All nonradioactive test samples were prepared for analysis on the Inductively Coupled Plasma Spectrophotometer or the Atomic Absorption Spectrophotometer.

The analytical results were used to calculate distribution coefficients and material balances. Material balances are performed to ensure that all radioactivity is accounted for in each of the samples. If a material balance does not close to within $10 \%$ of unity, it may indicate problems with precipitation, experimental technique, or perhaps cross-contamination between samples. Tests in which the material balance did not close to within $10 \%$ were typically repeated. 


\section{RESULTS AND DISCUSSION}

\section{Nitric Acid Extraction}

The amount of acid extracted by the organic solvent is important in that it gives an idea of flowsheet configuration and potential problems that may be encountered. Acid extracted by the organic solvent needs to be back-extracted in a scrub section or by the strip solution before any significant actinide stripping can occur. This is undesirable since several contacts may be dedicated to back-extracting acid, effectively increasing the number of stages required in the flowsheet.

A test was conducted which included four extraction contacts with acid concentrations ranging from $0.015 \mathrm{M}$ to $8 \mathrm{M}$ nitric acid. The aqueous and organic equilibrium acid concentrations obtained for all contacts during this test are plotted in Figure 2. The best fit linear equation for the data as determined from least squares analysis is given by:

$$
\log \left[\mathrm{H}^{+}\right]_{\text {org }}=\log \left[\mathrm{H}^{+}\right]_{\mathrm{aq}}-0.44
$$

An average acid extraction distribution coefficient can be obtained obtained by rearranging equation (4) and solving for $\mathrm{D}_{\text {acid }}=\left[\mathrm{H}^{+}\right]_{\mathrm{org}} /\left[\mathrm{H}^{+}\right]_{\mathrm{aq}}=10^{-0.44}=0.36$. This average acid distribution is attributted solely to nitric acid extraction by TBP in the solvent and is sufficiently low that scrubbing the organic to remove acid is likely unnecessary prior to actinide stripping.

Figure 2. Equilibrium organic vs. aqueous acid concentrations.

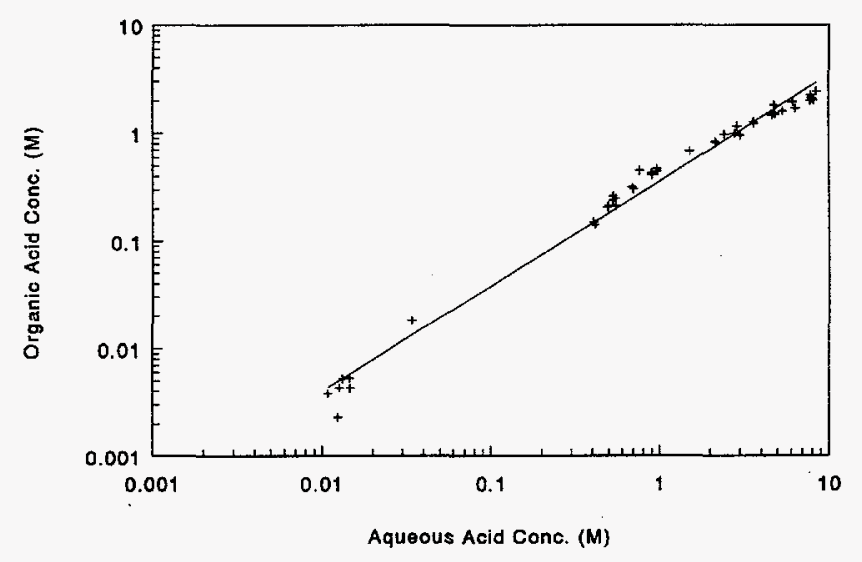




\section{Americium}

Preliminary studies were conducted with Am-241 to determine extraction characteristics as a function of nitric acid concentration. Individual batch contacts were performed with acid concentrations varying from $0.01 \underline{\mathrm{M}}$ to $8.0 \underline{\mathrm{M}}$ nitric acid and fresh organic solvent preequilibrated with the respective acid concentration. The results of this experiment are presented graphically in Figure 3. The resulting distribution coefficients indicate that Am may be stripped from the organic solvent simply by decreasing the nitric acid concentration of the strip solution. The distribution coefficients increased as the nitric acid concentration increased, with a maximum of $\mathrm{D}_{\mathrm{Am}} \sim 12$ at nitric acid concentrations above $5.0 \underline{\mathrm{M}} \mathrm{HNO}_{3}$.

Several tests were performed with americium-241 to determine the extraction distribution coefficients from the simulated SBW. Several strip solutions were tested to determine the $\mathrm{D}_{\mathrm{Am}}$ in back-extraction contacts with the americium loaded organic. The americium-241 tests included three pre-equilibration contacts with untraced SBW simulant prior to performing three extraction contacts with the traced simulant followed by three strip contacts. All batch contacts were performed with an organic to aqueous phase ratio of unity.

The americium-241 extraction test results, shown in Table 2, indicate higher extraction distribution coefficients than determined in the extraction of americium from nitric acid solutions. The extraction distribution coefficients averaged $\mathrm{D}_{\mathrm{Am}} \sim 23$, indicating about $96 \%$ extraction with each contact. The higher distribution coefficients are the result of salting effects from the higher nitrate concentrations in the simulated sodium bearing waste solution. At these

Figure 3. Americium distribution coefficients as a function of equilibrium acid concentration.

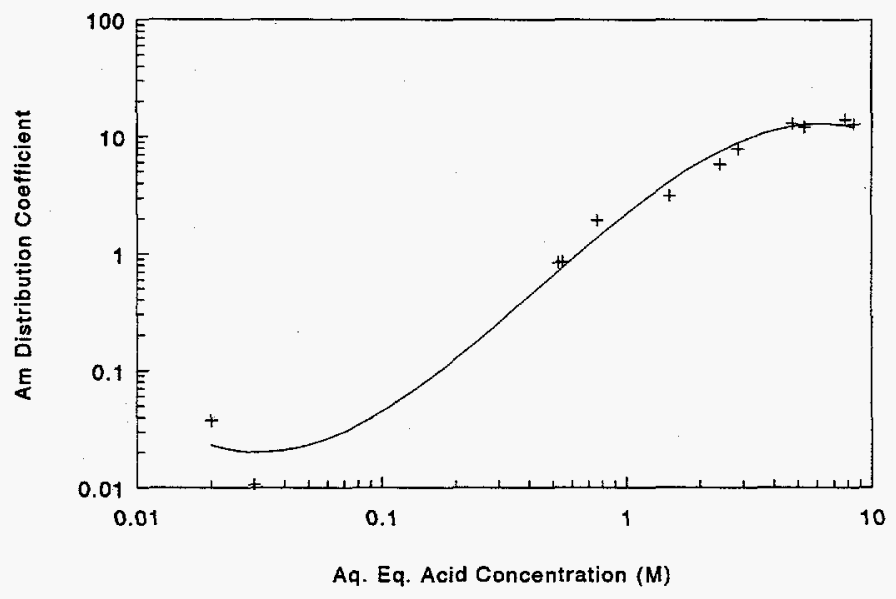


levels of extraction, $99.99 \%$ of the americium content in the actual SBW can easily be removed.

Three strip solutions, $0.04 \underline{\mathrm{M}}$ 1-hydroxyethane-1,1-diphosphonic acid (HEDPA) in 0.04 $\underline{\mathrm{M}}$ nitric acid $\left(\mathrm{HNO}_{3}\right), 0.01 \mathrm{M}$ oxalic acid $\left(\mathrm{H}_{2} \mathrm{C}_{2} \mathrm{O}_{4}\right)$ in $0.04 \underline{\mathrm{M}} \mathrm{HNO}_{3}$, and $0.05 \underline{\mathrm{M}}$ hydroxylamine nitrate (HAN) in $0.015 \underline{\mathrm{M}} \mathrm{HNO}_{3}$ were evaluated in this test. The $\mathrm{HAN} / \mathrm{HNO}_{3}$ strip solution was utilized to determine the stripping characteristics of a dilute nitric acid solution. The HAN is a reducing agent which has no effect on americium stripping.

The HEDPA/nitric acid solution achieved a strip distribution coefficient of 0.01 in the second contact, while the oxalic acid/nitric acid solution achieved a strip distribution coefficient of 0.007 on the third contact. The $\mathrm{HAN} / \mathrm{HNO}_{3}$ strip solution achieved a strip distribution coefficient of 0.17 on the third contact, verifying the results of previous americium tests indicating americium may be stripped with a dilute nitric acid solution. The strip distribution coefficients decrease with each subsequent contact since the first contacts are primarily stripping the extracted acid from the loaded organic solvent. The low distribution coefficients obtained with each of the strip solutions indicates any of these materials can easily be utilized in a flowsheet to recover virtually all of the extracted americium from the loaded organic solvent.

The mass balance of the third contact with the oxalic acid/nitric acid strip solution showed a $25 \%$ loss of the americium activity, suggesting the presence of an americium-oxalate precipitate. The americium mass is so small, it would be impossible to observe a precipitate. It is possible that the americium loss could be avoided by increasing the nitric acid concentration of the strip solution to about $0.2 \mathrm{M}$ in an attempt to keep the americium soluble in the strip solution.

Table 2. Americium distribution coefficients for extraction and for various strip solutions.

\begin{tabular}{|c|c|c|c|}
\hline Contact & $\begin{array}{c}\text { Test \#1 } \\
\mathrm{D}_{\mathrm{Am}} \\
\end{array}$ & $\begin{array}{c}\text { Test \#2 } \\
\mathrm{D}_{\mathrm{Am}} \\
\end{array}$ & $\begin{array}{c}\text { Test \#3 } \\
\mathrm{D}_{\mathrm{Am}} \\
\end{array}$ \\
\hline Extraction 1 & 22.54 & 23.39 & 23.11 \\
\hline Extraction 2 & 21.76 & 23.39 & 22.98 \\
\hline Extraction 3 & 23.45 & 22.97 & 22.69 \\
\hline Strip Solution: & $\begin{array}{c}0.04 \underline{\mathrm{M}} \mathrm{HEDPA} \text { in } \\
0.04 \underline{\mathrm{M}} \mathrm{HNO}_{3}\end{array}$ & $\begin{array}{c}0.05 \mathrm{M} \mathrm{H}_{2} \mathrm{C}_{2} \mathrm{O}_{4} \text { in } \\
0.01 \underline{\mathrm{M}} \mathrm{HNO}_{3}\end{array}$ & $\begin{array}{c}0.015 \mathrm{M} \mathrm{HNO}_{3} \text { in } \\
0.05 \underline{\mathrm{M}} \mathrm{HAN}\end{array}$ \\
\hline Strip 1 & 0.31 & 1.41 & 0.79 \\
\hline Strip 2 & 0.01 & 0.17 & 0.22 \\
\hline Strip 3 & ND & 0.007 & 0.17 \\
\hline
\end{tabular}

ND: Not determined; organic concnetrations were below analytical detedtion limits. 


\section{Plutonium}

Plutonium-238 tracer tests were performed to determine extraction characteristics from various concentrations of nitric acid. The solutions ranged in concentration from $0.01 \underline{\mathrm{M}}$ to $8 \underline{\mathrm{M}}$ $\mathrm{HNO}_{3}$. The results of this experiment are presented in Figure 4. The highest extraction distribution coefficient of $D_{P_{u}}=25$ was obtained at an equilibrium acid concentration of $7.23 \underline{\mathrm{M}}$ $\mathrm{HNO}_{3}$, while the lowest distribution coefficient of $\mathrm{D}_{\mathrm{Pu}_{u}}=0.09$ was observed at $0.01 \underline{\mathrm{M}} \mathrm{HNO}_{3}$. The test indicates that adequate plutonium extraction is possible with the DHDECMP organic solvent. The distribution coefficient of $\mathrm{D}_{\mathrm{Pu}}=0.09$ with $0.01 \mathrm{M} \mathrm{HNO}$ is low enough to indicate that the removal of plutonium from the DHDECMP organic solvent is possible with a dilute nitric acid solution.

Additional plutonium tracer tests were performed with Pu-238 and Pu-239 spiked into simulated SBW. The results of the tests are listed in Table 3. The difference in distribution coefficients between the two isotopes are due to the $\mathrm{Pu}-238$ being approximately $70 \%$ in the $\mathrm{Pu}^{+6}$ oxidation state and $30 \%$ in the $\mathrm{Pu}^{+4}$ state. The $\mathrm{Pu}-239$ tracer was predominantly in the $\mathrm{Pu}^{+4}$ state. The organic solvent has a stronger affinity for isotopes in the +4 state than the +6 state, as evidenced by the extraction distribution coefficients, which were a maximum of $D_{\mathrm{Pu}_{u}}=123$ for $\mathrm{Pu}-238$, and $\mathrm{D}_{\mathrm{Pu}_{\mathrm{u}}}=1489$ for Pu-239. The difference between the values of the distribution coefficients is greater than 1000; however, the difference in percent extraction corresponds to less than one percent between the two isotopes. The distribution coefficients are also much

Figure 4. Plutonium distribution coefficients as a function of equilibrium acid concentration.

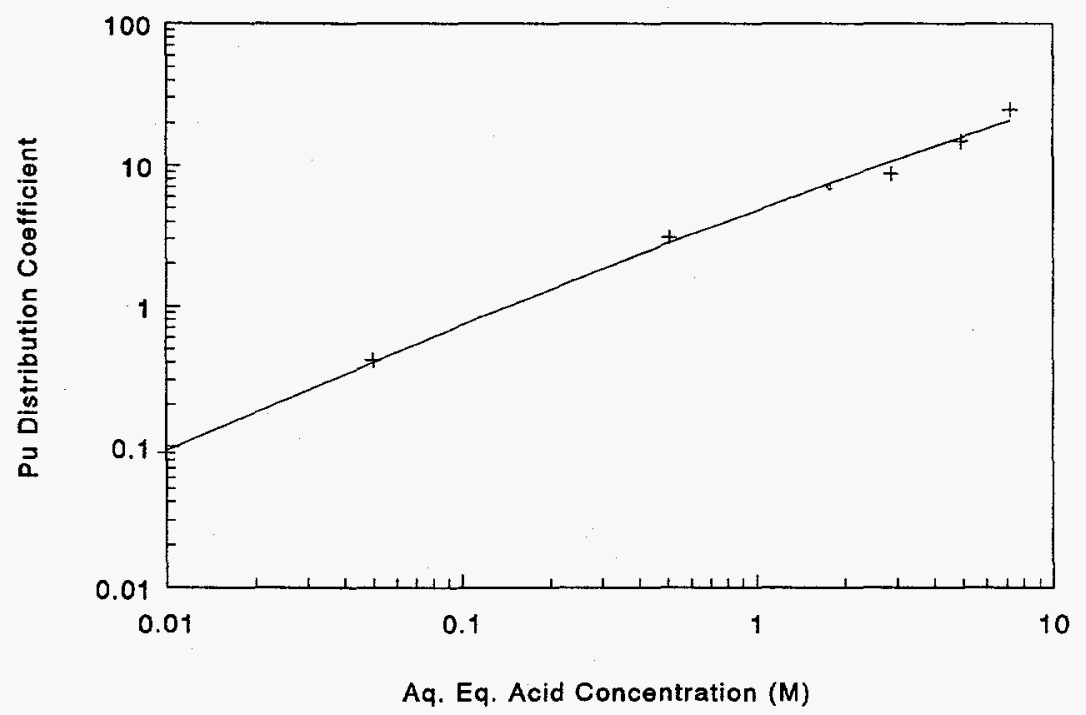


higher than the maximum $\mathrm{D}_{\mathrm{Pu}}=25$ observed in the tracer tests as a function of nitric acid concentration. The higher distributions found in the SBW tests are attributted to salting effects caused by the high nitrate concentration in the waste solution. Salting effects of the SBW simulant increase the solubility of the extractable species in the organic solvent, resulting in a corresponding increase in extraction distribution coefficients.

The three strip solutions tested were $0.015 \underline{\mathrm{M}}$ nitric acid, $0.02 \underline{\mathrm{M}}$ HEDPA in $0.01 \underline{\mathrm{M}}$ nitric acid and $0.05 \underline{\mathrm{M}}$ oxalic acid in $0.005 \underline{\mathrm{M}}$ nitric acid. Only the HEDPA/nitric acid and the oxalic acid/nitric acid solution effectively recovered the plutonium from the loaded organic solvent. The nitric acid strip solution was unsuccessful in stripping plutonium from the DHDECMP organic solvent, emphasizing the increased affinity of the extracted species for the organic solvent. The HEDPA/nitric acid solution achieved distribution coefficients of $\mathrm{D}_{\mathrm{Pu}} \sim 0.01$ in the first and second strip contacts. The oxalic acid/nitric acid solution achieved a distribution coefficient of $D_{\mathrm{Pu}} \sim 0.03$ on the second strip.

The analytical results from the third strip contacts with HEDPA/nitric acid and oxalic acid/nitric acid show an increase in distribution coefficients. This increase is the result of the low activities found in the organic phase after the first and second strip contacts. The accuracy of the analytical instrument decreases as the activity in each of the samples approaches the detection limit. The apparent increase in the distribution coefficient is a result of there being little or no activity left to detect in the organic and aqueous samples. The strip distribution coefficients observed with the $0.015 \underline{\mathrm{M}}$ nitric acid contacts increase because very little stripping is occuring. Almost all of the plutonium remained in the loaded organic solvent.

Table 3. Plutonium distribution coefficients with SBW simulant and various strip solutions.

\begin{tabular}{||c|c|c|c||}
\hline \hline Contact & $\mathrm{D}_{\mathrm{Pu}-239}$ & $\mathrm{D}_{\mathrm{Pu}-238}$ & $\mathrm{D}_{\mathrm{Pu}-239}$ \\
\hline Extraction 1 & 475 & 95.9 & 1028 \\
\hline Extraction 2 & 883 & 118 & 1422 \\
\hline Extraction 3 & 1144 & 123 & 1489 \\
\hline Strip Solution: & $0.015 \underline{\mathrm{M}} \mathrm{HNO}_{3}$ & $0.02 \underline{\mathrm{M}} \mathrm{HEDPA}$ in & $0.05 \mathrm{M} \mathrm{H}_{2} \mathrm{C}_{2} \mathrm{O}_{4}$ in \\
& & $0.01 \underline{\mathrm{M}} \mathrm{HNO}_{3}$ & $0.005 \underline{\mathrm{M} \mathrm{HN}_{3}}$ \\
\hline Strip 1 & 138 & 0.012 & 0.25 \\
\hline Strip 2 & 42.6 & 0.018 & 0.03 \\
\hline Strip 3 & 23.5 & 4.61 & 0.24 \\
\hline Strip 4 & 58.8 & $\mathrm{ND}$ & $\mathrm{NP}$ \\
\hline
\end{tabular}

ND: Not Determined; organic phase analysis below detection limits.

NP: Not Performed 


\section{Uranium}

Results of the uranium-233 tracer tests are listed in Table 4. The uranium extraction distribution coefficients averaged $D_{U} \sim 400$, in these tests. The average uranium extraction distribution coefficient corresponds to $99.8 \%$ extraction in each contact. The high levels of extraction facilitate the removal of uranium and the use of DHDECMP in a full scale process is very attractive since the decontamination requirements can easily be achieved.

Three strip solutions were tested; $0.04 \underline{\mathrm{M}}$ HEDPA in $0.04 \mathrm{M}$ nitric acid, $0.05 \underline{\mathrm{M}}$ oxalic acid in $0.01 \underline{\mathrm{M}}$ nitric acid, and $0.25 \underline{\mathrm{M}}$ sodium carbonate. Only the HEDPA/nitric acid solution and the oxalic acid/nitric acid solution were successful in recovering the uranium from the loaded organic solvent. The HEDPA/nitric acid solution resulted in a distribution coefficient of $\mathrm{D}_{U}=$ 0.04 on the first strip contact, while the oxalic acid/nitric acid solution achieved a distribution coefficient of $D_{U}=0.3$ on the third strip contact.

The sodium carbonate strip test was performed to determine the solutions stripping potential. Unfortunately, the sodium carbonate strip did not recover the uranium from the loaded organic solvent as evidenced by the high distribution coefficients of $D_{U} \sim 10$ to 25 .

Table 4. Uranium distribution coefficients with SBW simulant and various strip solutions.

\begin{tabular}{||c|c|c|c|c||}
\hline Contact & $\begin{array}{c}\text { Test \#1 } \\
\mathrm{D}_{\mathrm{U}}\end{array}$ & $\begin{array}{c}\text { Test\#2 } \\
\mathrm{D}_{\mathrm{U}}\end{array}$ & $\begin{array}{c}\text { Test \#3 } \\
\mathrm{D}_{\mathrm{U}}\end{array}$ & $\begin{array}{c}\text { Test \#4 } \\
\mathrm{D}_{\mathrm{U}}\end{array}$ \\
\hline Extraction 1 & 325 & 333 & 611 & 373 \\
\hline Extraction 2 & 365 & 361 & 488 & 379 \\
\hline Extraction 3 & 369 & 368 & 420 & 388 \\
\hline Strip & $0.04 \mathrm{M} \mathrm{HEDPA}$ & $0.05 \mathrm{M} \mathrm{H}_{2} \mathrm{C}_{2} \mathrm{O}_{4}$ & $0.05 \mathrm{M} \mathrm{H}_{2} \mathrm{C}_{2} \mathrm{O}_{4}$ & $0.25 \mathrm{M} \mathrm{Na}_{2} \mathrm{CO}_{3}$ \\
Solution: & $0.04 \mathrm{M} \mathrm{HNO}$ & $0.01 \mathrm{M} \mathrm{HNO}_{3}$ & $0.01 \underline{\mathrm{M} \mathrm{HNO}} \mathrm{H}_{3}$ & \\
\hline Strip 1 & 0.04 & 14.9 & 15.2 & 26.2 \\
\hline Strip 2 & 0.002 & 1.69 & 1.55 & 8.16 \\
\hline Strip 3 & $\mathrm{BDL}$ & 0.36 & 0.32 & 22.9 \\
\hline Wash 1 & $\mathrm{NP}$ & $\mathrm{NP}$ & 0.001 & $\mathrm{NP}$ \\
\hline Wash 2 & $\mathrm{NP}$ & $\mathrm{NP}$ & $\mathrm{ND}$ & $\mathrm{NP}$ \\
\hline
\end{tabular}

ND: Not Determined, organic phase analysis below detection limits.

NP: Not performed 


\section{Neptunium}

Results of the neptunium-239 tracer tests are listed in Table 5. The extraction distribution coefficients were a maximum in the third extraction contact, at $D_{\mathrm{Np}}=5.82$ which corresponds to $85 \%$ extraction. The extraction distribution coefficients are high enough that a process flowsheet can be tailored to remove much of the neptunium from the SBW.

Following the extraction contacts, the loaded organic solvent was divided into three separate aliquots which were contacted with different strip solutions. The strip solutions were $0.04 \underline{\mathrm{M}}$ HEDPA in $0.04 \underline{\mathrm{M}}$ nitric acid, $0.05 \underline{\mathrm{M}}$ oxalic acid in $0.01 \underline{\mathrm{M}}$ nitric acid, and $0.05 \underline{\mathrm{M}}$ sodium carbonate. Both the HEDPA/nitric acid and the oxalic acid/nitric acid solutions were very effective in recovering the neptunium from the loaded organic solvent. The HEDPA/nitric acid solution achieved a distribution coefficient of $\mathrm{D}_{\mathrm{Np}}=0.01$ on the first strip, while the oxalic acid/nitric acid solution achieved a distribution coefficient of $\mathrm{D}_{\mathrm{Np}}=0.09$ on the second strip contact. The sodium carbonate strip solution was ineffective in recovering significant amounts of the neptunium from the loaded organic solvent. With all sodium carbonate strip distribution coefficients above one, the largest amount of neptunium recovered was $42 \%$ on the first strip contact, decreasing to $14 \%$ on the third contact.

The distribution coefficients from the third strip with the HEDPA/nitric acid and the oxalic acid/nitric acid solution increased because the activities in each of the sample phases were close to the detection limit of the analytical instrument. The neptunium is so efficiently stripped from the loaded organic solvent that by the third strip contact, the activity from the neptunium present in the organic phase was at or below the background activity detected by the instrument. The sodium carbonate strip distribution coefficients increased, not because the activities in each of the phases were close to the analytical instruments detection limit, but because neptunium was not removed from the organic.

Table 5. Neptunium distribution coefficients with SBW simulant and various strip solutions.

\begin{tabular}{|c|c|c|c|}
\hline Contact & \multicolumn{3}{|c|}{$\overline{\mathrm{D}_{\mathrm{Np}}}$} \\
\hline Extraction 1 & \multicolumn{3}{|c|}{2.55} \\
\hline Extraction 2 & \multicolumn{3}{|c|}{4.16} \\
\hline Extraction 3 & \multicolumn{3}{|c|}{5.82} \\
\hline $\begin{array}{l}\text { Strip } \\
\text { Solution: }\end{array}$ & $\begin{array}{c}0.04 \underline{\mathrm{M}} \mathrm{HEDPA} \\
0.04 \underline{\mathrm{M} \mathrm{HNO}}\end{array}$ & $\begin{array}{c}0.05 \mathrm{M} \mathrm{H}_{2} \mathrm{C}_{2} \mathrm{O}_{4} \\
0.01 \underline{\mathrm{MNO}_{3}}\end{array}$ & $0.05 \underline{\mathrm{M} \mathrm{Na}} \mathrm{CO}_{3}$ \\
\hline Strip 1 & 0.01 & 0.18 & 1.40 \\
\hline Strip 2 & 0.56 & 0.09 & 2.19 \\
\hline Strip 3 & 0.81 & 1.89 & 6.04 \\
\hline
\end{tabular}




\section{Technetium}

Technetium-99, a pure beta emitter with a half-life of $2.13 \mathrm{E}+05$ years, is a long-lived fission product present in the SBW at a concentration of $1.01 \mathrm{E}-05 \mathrm{M}$ and an activity of $1.7 \mathrm{E}-04$ $\mathrm{Ci} / \mathrm{M}^{3}$. The technetium concentration in the $\mathrm{SBW}$ has an activity well below the $0.3 \mathrm{Ci} / \mathrm{M}^{3}$ limit required to achieve an NRC Class A low-level waste classification. Although the SBW already meets LLW classifications for Tc-99, it may be necessary to partition technetium with the actinides and prepare it for long term disposal with the high-level waste to meet disposal performance criteria since it is very mobile in the environment as the pertechnate ion, $\mathrm{TcO}_{4}{ }^{2-}$.

Tracer tests were conducted with technetium-99m to determine the extraction distribution coefficients from simulated SBW with the DHDECMP organic solvent. Technetium-99m is a metastable radionuclide with a six hour half life. The half life is so short that the radiotracer tests and analysis were performed within four half lives. This was done to ensure that enough activity was present in each of the analytical samples to be able to calculate extraction and strip distribution coefficients from the analytical results.

The results from the tests performed with technetium-99m are shown in Table 6. Each test included three pre-equilibration contacts with untraced SBW simulant followed by three extraction contacts with the Tc-99m spiked SBW simulant. The extraction contacts had an average extraction distribution coefficient of $\mathrm{D}_{\mathrm{Tc}}=1.26$, which corresponds to an average extraction of $56 \%$. At these levels of extraction, enough technetium is removed with the DHDECMP organic solvent to significantly reduce the amount that would end up in the lowlevel waste stream.

The technetium loaded organic solvents were split and two sets of strip contacts were performed with each of the aliquots. One set of tests included strip contacts with $0.04 \mathrm{M}$ HEDPA in $0.04 \mathrm{M} \mathrm{HNO}_{3}$ and with $0.05 \mathrm{M} \mathrm{H}_{2} \mathrm{C}_{2} \mathrm{O}_{4}$ in $0.01 \mathrm{M} \mathrm{HNO}_{3}$, while the other included

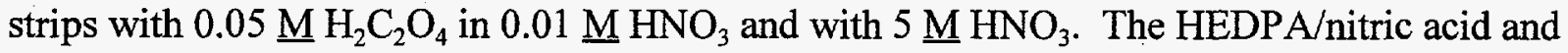
oxalic acid/nitric acid strip solutions were only able to recover an average of $14 \%$ of the extracted technetium. The $5 \mathrm{M}$ nitric acid strip solution recovered about $97 \%$ of the extracted technetium from the loaded organic solvent. A $5 \underline{\mathrm{M}}$, or perhaps more concentrated, nitric acid solution may be utilized to recover the extracted technetium from the loaded organic solvent.

One of the tests included two wash contacts with $0.25 \underline{\mathrm{M} \mathrm{Na}} \mathrm{CO}_{3}$ following three contacts with an oxalic acid/nitric acid strip solution. The sodium carbonate wash was able to remove $33 \%$ of the extracted Tc- $99 \mathrm{~m}$ with the first wash contact, and $26 \%$ of the remaining Tc-99m with the second contact, resulting in a cumulative recovery of about $50 \%$ of the extracted technetium. The levels of recovery with the sodium carbonate wash solution are not as good as those achieved with the $5.0 \underline{\mathrm{M}}$ nitric acid solution, but may be adequate to ensure technetium does not build up in the DHDECMP organic solvent. 
Table 6. Technetium distribution coefficients with simulated SBW and various strip solutions.

\begin{tabular}{|c|c|c|c|c|}
\hline Contact & \multicolumn{4}{|c|}{$\mathrm{D}_{\mathrm{Tc}}$} \\
\hline Extraction 1 & \multicolumn{4}{|c|}{1.29} \\
\hline Extraction 2 & \multicolumn{4}{|c|}{1.26} \\
\hline Extraction 3 & \multicolumn{4}{|c|}{1.26} \\
\hline Strip Solution: & $\begin{array}{c}0.04 \underline{\mathrm{M}} \mathrm{HEDPA} \\
0.04 \underline{\mathrm{M}} \mathrm{HNO}_{3}\end{array}$ & $\begin{array}{c}0.05 \underline{\mathrm{M}} \mathrm{H}_{2} \mathrm{C}_{2} \mathrm{O}_{4} \\
0.01 \underline{\mathrm{M}} \mathrm{HNO}_{3}\end{array}$ & $\begin{array}{c}0.05 \underline{\mathrm{M} \mathrm{H}_{2} \mathrm{C}_{2} \mathrm{O}_{4}} \\
0.01 \underline{\mathrm{M}} \mathrm{HNO}_{3}\end{array}$ & $5.0 \underline{\mathrm{M} \mathrm{HNO}}$ \\
\hline Strip 1 & 15.6 & 21.0 & 14.8 & 0.57 \\
\hline Strip 2 & 14.1 & 25.8 & 19.9 & 0.46 \\
\hline Strip 3 & 25.4 & 22.9 & 22.9 & 0.45 \\
\hline Wash Solution: & \multirow{3}{*}{ NP } & \multirow{3}{*}{ NP } & $0.25 \mathrm{M} \mathrm{Na}_{2} \mathrm{CO}_{3}$ & \multirow{3}{*}{ NP } \\
\hline Wash 1 & & & 1.99 & \\
\hline Wash 2 & & & 2.79 & \\
\hline
\end{tabular}

NP $=$ Not Performed

\section{Mercury}

An initial test with mercury-203 was performed to determine extraction characteristics as a function of nitric acid concentration. Nitric acid concentrations ranging from $0.11 \mathrm{M}$ to $8.32 \mathrm{M}$ $\mathrm{HNO}_{3}$, were utilized. The extraction distribution coefficient as shown in Figure 5, appears to decrease with increased nitric acid concentrations. The highest distribution coefficient of $\mathrm{D}_{\mathrm{Hg}}=$ 30.8 , was achieved at an equilibrium acid concentration of $0.44 \mathrm{M} \mathrm{HNO}_{3}$, while the lowest distribution coefficient of $\mathrm{D}_{\mathrm{Hg}}=0.35$ was measured at the higher nitric acid concentration. The results indicate that mercury may be recovered from the loaded organic solvent with nitric acid solutions above $5 \underline{\mathrm{M}} \mathrm{HNO}_{3}$.

Two tests were performed to determine the extraction characteristics of mercury-203 from simulated SBW and recovery from the loaded organic solvent. The results are outlined in Table 7. Extraction contacts in the first test were performed with only the stable mercury in the SBW simulant, followed by stripping contacts with $3 \underline{M}, 5 \underline{M}$, and $8 \underline{M}$ nitric acid. The solvent was divided into three aliquots, and contacted three times with each of the nitric acid solutions.

The Hg extraction distributions from the first test decreased in each subsequent contact, culminating with $D_{\mathrm{Hg}}=9.87$ on the third extraction. This decrease in extraction distribution likely resulted since the organic solvent was not pre-equilibrated prior to performing the test. 
Figure 5. Mercury distribution coefficients as a function of equilibrium acid concentration.

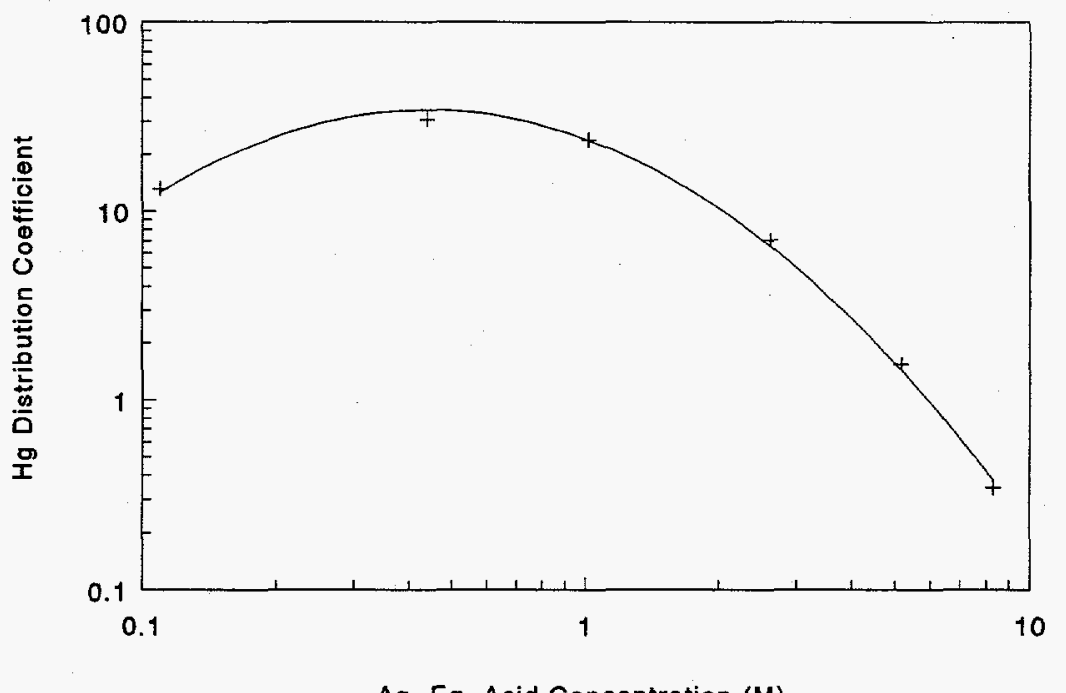

Aq. Eq. Acid Concentration (M)

The mercury scrub distribution coefficients, ranged from $D_{\mathrm{Hg}}=1.78$ to 2.18 with $5 \underline{\mathrm{M}}$ nitric acid, and $\mathrm{D}_{\mathrm{Hg}}=0.57$ to 0.99 with an $8 \underline{\mathrm{M}}$ nitric acid concentration. A selective mercury scrub with the high acid solutions may be performed to ensure mercury is partitioned from the extracted actinides. At this range, solvent loading can be prevented, although the high concentration of nitric acid may not be recommended for use with the organic solvent unless the effects of acid hydrolysis are found to be negligible.

A second test was performed with mercury-203. The test results, also shown in Table 7, included three pre-equilibration contacts with mercury free SBW simulant, followed by three extraction contacts with the traced simulant. The extraction distribution coefficients averaged $\mathrm{D}_{\mathrm{Hg}} \sim 8.7$, indicating approximately $90 \%$ extraction with each contact. At these levels of extraction, mercury can easily load the organic solvent if not efficiently recovered.

Following the three extractions, three contacts were performed with $0.04 \mathrm{M}$ HEDPA in

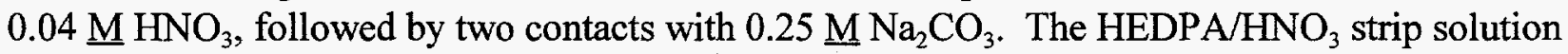
did not remove the extracted mercury from the organic phase; however, $55 \%$ of the mercury was recovered in the first sodium carbonate contact from the loaded organic. The second wash contact performed with the sodium carbonate did not recover any of the remaining mercury from the DHDECMP organic solvent. The mercury distribution coefficient for the second sodium 
Table 7. Mercury distribution coefficients with simulated SBW and various strip solutions.

\begin{tabular}{|c|c|c|c|c|c|}
\hline Contact & \multicolumn{3}{|c|}{$\mathrm{D}_{\mathrm{Hg}}$} & \multicolumn{2}{|c|}{$\mathrm{D}_{\mathrm{Hg}}$} \\
\hline Extraction 1 & \multicolumn{3}{|c|}{26.3} & \multicolumn{2}{|c|}{7.47} \\
\hline Extraction 2 & \multicolumn{3}{|c|}{12.9} & \multicolumn{2}{|c|}{9.21} \\
\hline Extraction 3 & \multicolumn{3}{|c|}{9.87} & \multicolumn{2}{|c|}{9.33} \\
\hline $\begin{array}{l}\text { Contact } \\
\text { Solution }\end{array}$ & $3 \mathrm{M} \mathrm{HNO}_{3}$ & $5 \underline{\mathrm{M}} \mathrm{HNO}_{3}$ & $8 \underline{\mathrm{M} \mathrm{HNO}_{3}}$ & $\begin{array}{c}0.04 \underline{\mathrm{M}} \mathrm{HEDPA} \\
0.04 \underline{\mathrm{M} \mathrm{HNO}_{3}}\end{array}$ & $\begin{array}{r}0.25 \underline{\mathrm{M}} \\
\mathrm{Na}_{2} \mathrm{CO}_{3}\end{array}$ \\
\hline Strip 1 & 7.35 & 2.18 & 0.62 & 52 & 0.83 \\
\hline Strip 2 & 6.92 & 1.78 & 0.57 & 96.8 & 34.6 \\
\hline Strip 3 & 6.58 & 1.9 & 0.99 & 137 & $\mathrm{NP}$ \\
\hline
\end{tabular}

NP $=$ Not Performed

carbonate contact of $\mathrm{D}_{\mathrm{Hg}}=34.6$ was determined by material balance since $\mathrm{Hg}$ was not detected in the aqueous sodium carbonate sample. The recovered mercury from the first wash contact is adequate to prevent solvent loading following multiple recycles.

\section{Zirconium}

The results reported in Table 8 for the zirconium tests were determined by conducting three pre-equilibration contacts of the organic with $1.5 \underline{\mathrm{M}}$ nitric acid prior to performing the extraction contacts with SBW simulant traced with the zirconium-95 radioisotope. The zirconium-95 extraction distribution coefficients averaged $\mathrm{D}_{\mathrm{Zr}} \sim 0.99$. This results in half of the zirconium in the feed solution following the actinides and being recovered in the strip section by either of the tested strip solutions. The first contact with $0.04 \underline{\mathrm{M}} \mathrm{HEDPA} / 0.04 \underline{\mathrm{M} \mathrm{HNO}}, 0.05 \underline{\mathrm{M}}$ $\mathrm{H}_{2} \mathrm{C}_{2} \mathrm{O}_{4} / 0.01 \underline{\mathrm{M}} \mathrm{HNO}_{3}$, and $0.1 \underline{\mathrm{M} \mathrm{NH}} \mathrm{F}_{4} / 1.0 \mathrm{M} \mathrm{HNO}_{3}$ all resulted in a distribution coefficient of $\mathrm{D}_{\mathrm{zr}}=0.002$ for zirconium.

The contacts with $\mathrm{NH}_{4} \mathrm{~F} / \mathrm{HNO}_{3}$, were performed to selectively scrub the zirconium from the actinides. The scrub solution achieved a $\mathrm{Zr}$ scrub distribution coefficient of $\mathrm{D}_{\mathrm{Zr}}=0.002$, essentially recovering all of the zirconium in the first contact. The increased distribution coefficients in the second and third scrub contacts are attributed to the low zirconium concentration in the organic phase after the first contact. The $\mathrm{NH}_{4} \mathrm{~F} / \mathrm{HNO}_{3}$ scrub solution will not remove the actinides from the loaded organic solvent due to the high nitric acid concentration. Depending on the impact of the extracted zirconium on the high-level waste stream, a scrub section may be deemed feasible. Until the impacts of zirconium are determined, a scrub section will not be included in any of the flowsheets developed for SBW. 
Table 8. Zirconium distribution coefficients with simulated SBW and various strip solutions.

\begin{tabular}{|c|c|c|c|}
\hline Contact & & $\mathrm{D}_{\mathrm{Zr}}$ & \\
\hline Extraction 1 & 0.92 & 0.92 & 0.97 \\
\hline Extraction 2 & 0.99 & 0.99 & 1.05 \\
\hline Extraction 3 & 0.99 & 0.99 & 1.10 \\
\hline Strip Solution: & $\begin{array}{c}0.04 \underline{\mathrm{M}} \mathrm{HEDPA} \\
0.04 \underline{\mathrm{M}} \mathrm{HNO}_{3}\end{array}$ & $\begin{array}{c}0.05 \mathrm{M} \mathrm{H}_{2} \mathrm{C}_{2} \mathrm{O}_{4} \\
0.01 \underline{\mathrm{M} H \mathrm{HNO}_{3}}\end{array}$ & $\begin{array}{l}0.1 \mathrm{M} \mathrm{NH}_{4} \mathrm{~F} \\
1.0 \underline{\mathrm{M}} \mathrm{HNO}_{3}\end{array}$ \\
\hline Strip 1 & 0.002 & 0.002 & 0.002 \\
\hline Strip 2 & 0.86 & 0.79 & 0.71 \\
\hline Strip 3 & ND & $\mathrm{ND}$ & 1.03 \\
\hline
\end{tabular}

ND: Not Determined; organic phase analysis below detection limits.

\section{Extraction Of Matrix Components}

A test was performed with the SBW simulant to determine the extraction distribution coefficients of inert elemental constituents present in the waste solution. Three pre-equilibration contacts were performed with $1.0 \underline{\mathrm{M}} \mathrm{HNO}_{3}$ prior to conducting three extraction contacts with the SBW simulant. The aqueous raffinate was analyzed for aluminum, calcium, chromium, zirconium, iron, cadmium, potassium, and sodium. The distribution coefficients were then calculated by mass balance since organic solutions cannot be directly analyzed.

The extraction distribution coefficients shown in Table 9 indicate the inert elemental constituents all have distribution coefficients of less than one. The zirconium distribution coefficients were found to average $D_{z r} \sim 0.1$, much lower than the $D_{z r} \sim 0.99$ found from the $Z r-95$ tracer tests. The difference might be due to speciation between the zirconium isotope used for the tracer tests and that in the SBW simulant.

Table 9. Extraction distribution coefficients for non-radioactive components.

\begin{tabular}{||l|c|c|c|c|c|c|c|c||}
\hline \multicolumn{1}{|c|}{ Contact } & $\mathrm{D}_{\mathrm{Al}}$ & $\mathrm{D}_{\mathrm{Ca}}$ & $\mathrm{D}_{\mathrm{Cr}}$ & $\mathrm{D}_{\mathrm{Zr}}$ & $\mathrm{D}_{\mathrm{Fe}}$ & $\mathrm{D}_{\mathrm{Cd}}$ & $\mathrm{D}_{\mathrm{K}}$ & $\mathrm{D}_{\mathrm{Na}}$ \\
\hline Extraction 1 & 0.086 & 0.23 & 0.17 & 0.075 & 0.095 & 0.11 & 0.021 & 0.049 \\
\hline Extraction 2 & 0.085 & 0.23 & 0.28 & 0.16 & 0.14 & 0.22 & 0.043 & 0.076 \\
\hline Extraction 3 & 0.091 & 0.26 & 0.41 & 0.11 & 0.18 & 0.33 & 0.064 & 0.16 \\
\hline
\end{tabular}




\section{Proposed Flowsheet For The Treatment Of SBW}

The actinide, mercury, technetium, and zirconium distribution coefficient results determined in the batch tracer tests were utilized to propose a potential flowsheet for the treatment of SBW. The proposed flowsheet is shown in Figure 6 and includes extraction, strip, wash and re-acidification sections.

The number of extraction and strip stages, and the solution flowrates, were determined by modeling the flowsheet using the Generic TRUEX Model (GTM) [14]. The GTM was developed at Argonne National Laboratory (ANL-East) and is routinely used to model the CMPO extraction process at the ICPP. Laboratory distribution coefficients obtained from the batch contacts described previously were input into the GTM and a flowsheet was developed (see Figure 6). The flowsheet consists of five stages of extraction at an $\mathrm{O} / \mathrm{A}$ of 0.33 , four stages of $0.04 \underline{\mathrm{M}}$ HEDPA strip at an O/A of 1.0, two stages of $0.25 \underline{\mathrm{M}}$ sodium carbonate wash at an O/A of 1.0 , and one stage of $0.1 \underline{\mathrm{M}}$ nitric acid rinse at an $\mathrm{O} / \mathrm{A}$ of 3.0.

With this flowsheet, the GTM predicts DF's of 4757, 2.1E06, 1.1E+06, and 23 for Am, $\mathrm{Pu}, \mathrm{U}$, and $\mathrm{Np}$, respectively. With these DF's, the actinide activity would be reduced to well below the NRC Class A LLW limit of $10 \mathrm{nCi} / \mathrm{g}$. Mercury builds up in the solvent to twice the concentration of $\mathrm{Hg}$ in the feed, with $97 \%$ exiting in the raffinate and sodium carbonate wash streams. Thirty-three percent of the $\mathrm{Zr}$ is extracted from the SBW and exits in the strip product. Technetium builds up in the solvent to $74 \%$ of the SBW feed concentration, with $16 \%$ exiting in the sodium carbonate wash and $82 \%$ remaining in the raffinate. This flowsheet was subsequently tested in the 5.5-cm Centrifugal Contactor Mockup and the results are presented elsewhere [15]. 
Figure 6. Proposed flowsheet for the treatment of SBW with $0.75 \underline{\mathrm{M}}$ DHDECMP/1.4 $\mathrm{M}$ TBP in Isopar $\mathrm{L}^{\circledR}$.
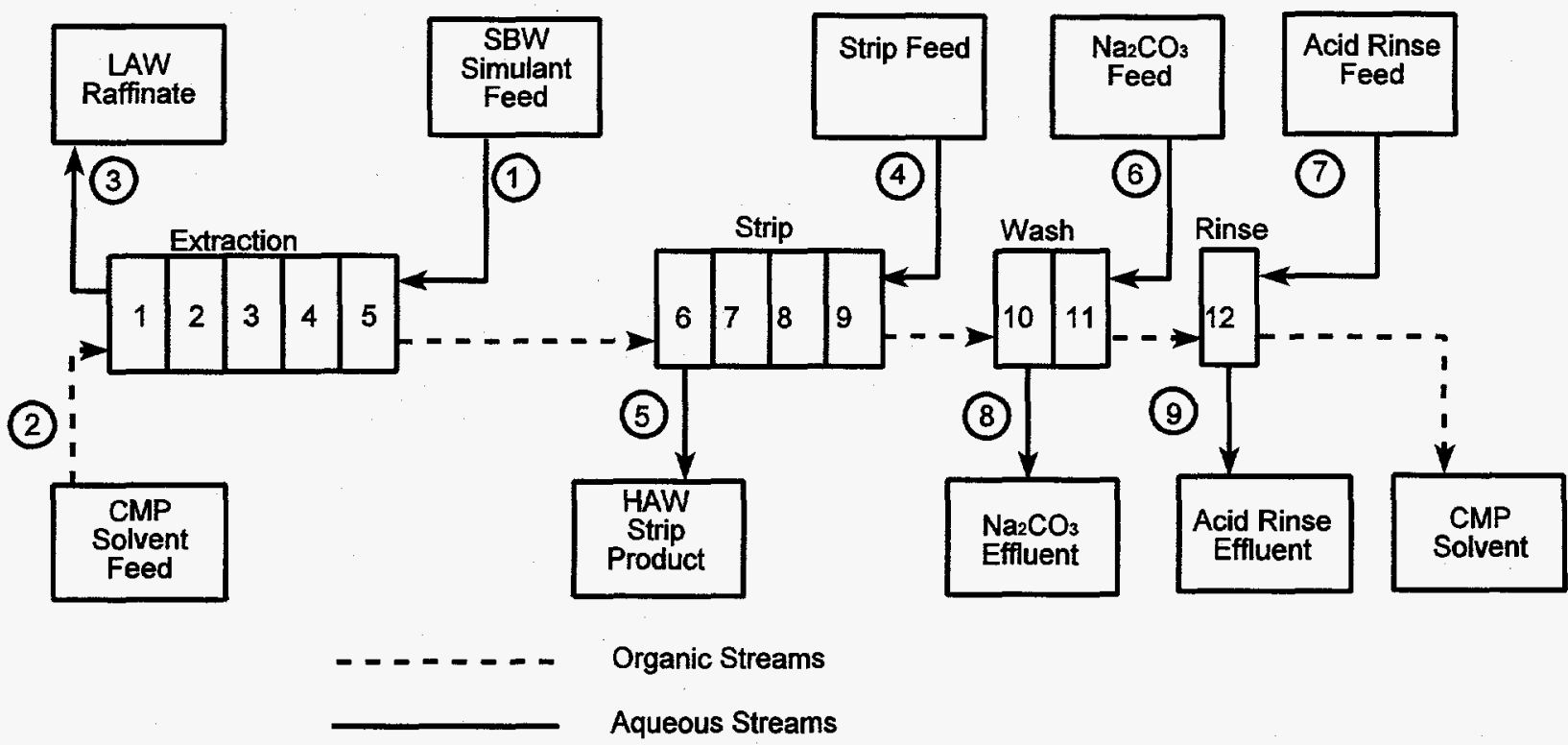

\begin{tabular}{|c|c|c|c|c|c|c|c|c|c|}
\hline $\begin{array}{l}\text { Comp. } \\
\text { Stream: }\end{array}$ & $\begin{array}{c}\text { Sodium } \\
\text { Waste } \\
\text { Feed } \\
\text { (Molar) } \\
1\end{array}$ & $\begin{array}{c}\text { CMP } \\
\text { Solvent } \\
\text { Feed } \\
\text { (Molar) } \\
2\end{array}$ & $\begin{array}{c}\text { LAW } \\
\text { Raffinate } \\
\text { (Molar) } \\
3\end{array}$ & $\begin{array}{l}\text { HEDPA } \\
\text { Strip } \\
\text { Feed } \\
\text { (Molar) } \\
4\end{array}$ & $\begin{array}{c}\text { HAW } \\
\text { Strip } \\
\text { Product } \\
\text { (Molar) } \\
5\end{array}$ & $\begin{array}{c}\text { Carbonate } \\
\text { Wash } \\
\text { Feed } \\
\text { (Molar) } \\
6\end{array}$ & $\begin{array}{c}\text { Acid } \\
\text { Rinse } \\
\text { Feed } \\
\text { (Molar) } \\
7\end{array}$ & $\begin{array}{c}\text { Carbonate } \\
\text { Wash } \\
\text { Effluent } \\
\text { (Molar) } \\
8\end{array}$ & $\begin{array}{c}\text { Acid } \\
\text { Rinse } \\
\text { Effluent } \\
\text { (Molar) } \\
9\end{array}$ \\
\hline Flowrate & 1 & 0.33 & 1 & 0.33 & 0.33 & 0.33 & 0.11 & 0.33 & 0.11 \\
\hline $\mathrm{HNO}_{3}$ & 1.5 & & & 0.01 & & & 0.10 & & \\
\hline $\mathrm{Na}_{2} \mathrm{CO}_{3}$ & & & & & & 0.25 & & & \\
\hline HEDPA & & & & 0.04 & & & & & \\
\hline $\mathrm{Hg}$ & 2.0E-03 & $3.96 \mathrm{E}-03$ & $4.96 \mathrm{E}-04$ & & $1.59 \mathrm{E}-04$ & & & 4.39E-03 & Trace \\
\hline $\mathrm{Zr}$ & $3.0 \mathrm{E}-03$ & & $2.01 \mathrm{E}-03$ & & $3.00 \mathrm{E}-03$ & & & Trace & Trace \\
\hline $\mathrm{Tc}$ & $1.0 \mathrm{E}-05$ & $7.39 \mathrm{E}-06$ & $8.17 \mathrm{E}-06$ & & $8.20 \mathrm{E}-07$ & & & $4.74 \mathrm{E}-06$ & Trace \\
\hline \multicolumn{10}{|l|}{ Actinides } \\
\hline $\mathrm{Am}$ & $8.8 \mathrm{E}-08$ & & $1.85 \mathrm{E}-11$ & & $2.67 \mathrm{E}-07$ & & & Trace & Trace \\
\hline $\mathrm{Pu}$ & $2.3 \mathrm{E}-05$ & & $1.08 \mathrm{E}-11$ & & $6.97 \mathrm{E}-05$ & & & Trace & Trace \\
\hline $\mathrm{U}$ & $3.8 \mathrm{E}-04$ & & $3.46 \mathrm{E}-10$ & & $1.15 \mathrm{E}-03$ & & & Trace & Trace \\
\hline $\mathrm{Np}$ & $3.2 \mathrm{E}-06$ & & $1.37 \mathrm{E}-07$ & & $9.28 \mathrm{E}-06$ & & & Trace & Trace \\
\hline
\end{tabular}




\section{Phase Disengagement Studies}

Phase disengagement was evaluated by calculating the dispersion numbers for each stage contact in support of the proposed centrifugal contactor pilot plant tests. Dispersion numbers were calculated according to the equation:

$$
N_{D i}=\frac{1}{t_{B}}(\Delta Z / g)^{1 / 2}
$$

where $t_{B}$ is the time in seconds required for the phases to visually separate, $\Delta Z$ is the total height of the two phases in meters, and $g$ is the gravitational constant, $9.81 \mathrm{~m} / \mathrm{s}^{2}$ [14].

The dispersion number is utilized to predict the phase disengagement of a centrifugal contactor system by correlating the dispersion number to the contactor capacity, rotor speed and geometry [12]. When a pair of immiscible liquids exhibit characteristics that achieve a dispersion number of $\mathrm{N}_{\mathrm{Di}} \geq 8 \mathrm{E}-04$, the two phase system can be utilized in a centrifugal contactor system with rotor diameters of $2,4,9,12$, and 25 centimeters without significant problems [12]. The data in Table 10 were obtained utilizing three extraction contacts with simulated SBW, five strip contacts with $0.04 \underline{\mathrm{M}}$ HEDPA in $0.01 \underline{\mathrm{M}}$ nitric acid, two wash contacts with $0.25 \underline{\mathrm{M}}$ sodium carbonate, and one re-acidification contact with $0.1 \mathrm{M} \mathrm{HNO}_{3}$. The dispersion numbers reported in Table 10 were all above the recommended number of $8 \mathrm{E}-04$ with the exception of the dispersion number for the $0.1 \underline{\mathrm{M}} \mathrm{HNO}_{3}$, which was $3.1 \mathrm{E}-04$. This low dispersion number indicates phase separation problems could be encountered in the re-acidification section. This was confirmed in subsequent flowsheet testing using centrifugal contactors [15].

Table 10. Dispersion numbers from extraction, strip, wash, and re-acidification contacts.

\begin{tabular}{||c|c|c||}
\hline Contact & $\begin{array}{c}\text { Organic to Aqueous } \\
\text { Phase Ratio }\end{array}$ & $\begin{array}{c}\text { Dispersion } \\
\text { Number }\end{array}$ \\
\hline Extraction 1 & 0.3 & $16.5 \mathrm{E}-04$ \\
\hline Extraction 2 & 0.3 & $18.8 \mathrm{E}-04$ \\
\hline Extraction 3 & 0.3 & $18.6 \mathrm{E}-04$ \\
\hline Strip 1 & 3.0 & $10.1 \mathrm{E}-04$ \\
\hline Strip 2 & 3.0 & $9.9 \mathrm{E}-04$ \\
\hline Strip 3 & 3.0 & $9.7 \mathrm{E}-04$ \\
\hline Strip 4 & 3.0 & $8.6 \mathrm{E}-04$ \\
\hline Strip 5 & 3.0 & $9.0 \mathrm{E}-04$ \\
\hline Wash 1 & 3.0 & $9.0 \mathrm{E}-04$ \\
\hline Wash 2 & 3.0 & $11.0 \mathrm{E}-04$ \\
\hline Re-acidification 1 & 3.0 & $3.1 \mathrm{E}-04$ \\
\hline
\end{tabular}




\section{CONCLUSIONS}

The main priority of this research was determining if the actinides could be efficiently partitioned from SBW resulting in a LLW fraction below the NRC Class A requirements of 10 $\mathrm{nCi} / \mathrm{g}$. The batch radioactive tracer tests indicated the actinides had sufficiently high distribution coefficients to effect such a separation.

Many tests were performed without indication of adverse physical problems such as third phase formation. This was a major criterium that would have nullified the positive results, making the organic solvent unsuitable for use in a solvent extraction system. The precipitation of any extracted species would have also made the organic solvent unsuitable. The bulk of the inert elemental constituents accounted for less than one percent of the extracted metals, with the exception of zirconium and mercury. Zirconium and mercury accounted for approximately $4 \%$, and $99.7 \%$ respectively, of the inert elemental constituents that were extracted. Even at these levels of extraction, zirconium and mercury did not cause any precipitation problems.

Zirconium extraction was initially a major concern. As previously stated, $\mathrm{Zr}$ could precipitate and cause operational problems; however, this did not happen and the major concern became whether enough $\mathrm{Zr}$ was extracted to necessitate a scrub section to selectively partition $\mathrm{Zr}$ from the actinides. This could be accomplished by performing a $3 \underline{\mathrm{M}}$ nitric acid scrub to remove the extracted zirconium from the loaded organic solvent. It was determined that the low concentrations of zirconium in the SBW, combined with the low distribution coefficients, would not require the addition of a scrub section.

Mercury was a concern due to marginal back-extraction with $\mathrm{Na}_{2} \mathrm{CO}_{3}$ or $8 \underline{\mathrm{M}} \mathrm{HNO}_{3}$ solutions. The first sodium carbonate wash contact in the batch tests achieved a distribution coefficient of $\mathrm{D}_{\mathrm{Hg}}=0.88$, about a $53 \%$ removal. The mercury recovered may be enough to preclude the $\mathrm{Hg}$ loading of the organic solvent. If not, alternatives such as a high acid scrub may be necessary. The $8 \underline{\mathrm{M}}$ nitric acid scrub achieved slightly better results than the sodium carbonate wash solution since the distribution coefficients averaged about 0.5 for each contact. The use of a concentrated nitric acid solution is a concern because of the hydrolytic effects, which may cause acid degradation of the organic solvent. The potential effects will have to weighed in comparison to the benefits if a high nitric acid scrub is to be used.

A major emphasis was to find a suitable stripping solution that would back-extract the actinides from the loaded organic solvent. Two solutions were tested for this research, $0.04 \mathrm{M} 1$ hydroxyethane-1, 1-diphosphonic acid (HEDPA) in $0.04 \mathrm{M}$ nitric acid and $0.01 \mathrm{M}$ oxalic acid in $0.04 \mathrm{M}$ nitric acid. There was a question with the use of the oxalic acid/nitric acid solution since the material balance of some tests with americium had more than a twenty percent loss, indicating the americium may have precipitated. The oxalic acid/nitric acid solution was also unable to back-extract uranium. The HEDPA/nitric acid solution alleviated these problems and indicated very efficient gross actinide removal from the loaded organic solvent. 


\section{RECOMMENDATIONS}

As a result of this study, the initial recommendation was to test the $0.75 \mathrm{M} \mathrm{CMP} \mathrm{solvent}$ on simulated SBW in continuous, countercurrent mode using the $5.5 \mathrm{~cm}$ Centrifugal Contactor Pilot Plant located at the ICPP. A subsequent test based on the proposed flowsheet indicated phase disengagement properties of the solvent were unacceptable in the acid re-acidification section [15]. This behavior was attributed to poor hydrodynamic properties of the organic solvent. Potential solutions to alleviate this problem were considered, including: decreasing the extractant concentration from $0.75 \underline{\mathrm{M}} \mathrm{CMP}$ to $0.5 \underline{\mathrm{M}}$ or $0.25 \underline{\mathrm{M}} \mathrm{CMP}$; increasing the TBP concentration in the solvent; or altering the diluent from Isopar $\mathrm{L}^{\circledR}$ to a similar hydrocarbon. The only option actively explored was the reduction in CMP concentration. A preliminary scoping study was performed, indicating that a reduction to $0.5 \underline{\mathrm{M}} \mathrm{CMP}$ in the solvent would potentially alleviate the phase disengagement problems in the flowsheet, yet keep the actinide (particularly $\mathrm{Am}$ ) distributions large enough to effect the required separation. Further reduction of extractant concentration to $0.25 \mathrm{M}$ CMP resulted in substantially decreased extraction distributions for americium from the simulated SBW. Consequently, the final recommendation was to lower CMP concentration in the solvent to $0.5 \underline{\mathrm{M}}$. A test was subsequently performed in the $5.5 \mathrm{~cm}$ Centrifugal Contactor Mockup with anticipated success [15].

It is of utmost importance to note that the problems encountered with the $0.75 \mathrm{M} \mathrm{CMP} /$ $1.0 \underline{\mathrm{M}} \mathrm{TBP} /$ Isopar $\mathrm{L}^{\circledR}$ solvent do not alter the usefulness of the data obtained in this study. The same behavior and trends are anticipated, regardless of the method employed to enhance phase disengagement properties of the solvent. All data obtained in this report are pertinent to and will be of value in continued development efforts. 

(1) 


\section{REFERENCES}

1. Berreth, J. R., "Inventories and Properties of ICPP Calcined High-Level Waste", WINCO-1050, February 1988.

2. Olson, A. L., et.al., "Evaluation and Selection of Aqueous-Based Technologies for Partitioning Radionuclides From ICPP Calcine", WINCO-1171, February 1993.

3. Murphy, J. A., et.al., "ICPP Radioactive Liquid and Calcine Waste Technologies Evaluation Final Report and Recommendation", INEL-94/0119, April 1995.

4. Sidall, T. H., III, "Bidentate Organophosphorus Compounds as Extractants - II," Extraction Mechanisms For Cerium (III) Nitrate," Journal of Inorganic and Nuclear Chemistry, Vol. 26, No. 11, p. 1991, November, 1964.

5. McIsaac, L. D., et al., "Actinide Removal from ICPP Wastes", ICP-1080, August 1975.

6. McIsaac, L. D., et al., "Study of Bidentate Compounds for Separation of Actinides from Commercial LWR Reprocessing Waste", ICP-1180, Feb. 1979.

7. Maxey, H. R., et al., "Removal of Actinides from ICPP Fuel Reprocessing Wastes Engineering Studies Terminal Report", ENICO-1057, September 1980.

8. Marsh, S. F., Yarbro, S. L., "Comparative Evaluation of DHDECMP and CMPO as Extractants for Recovering Actinides from Nitric Acid Waste Streams", LA-11191, February 1988.

9. Lumetta, G. J., Rapko, B. M., "Extraction of Transuranic Elements with a Dihexyl-N, Ndiethylcarbamoylmethyl phosphonate/tributyl phosphate System-Initial Investigations", Solvent Extraction and Ion Exchange, 12(5), 1994.

10. Krupa, J. F., et al., "Actinide Partitioning from ICPP Waste: An Investigation of Methods to Eliminate Mercury Interference", ICP-1181, March 1979.

11. Law, J. D., Herbst, R. S., "TRUEX Flowsheet Development as Applied to ICPP SodiumBearing Waste Using Centrifugal Contactors", INEL-95/0130, February 1995.

12. Leonard, R. A., Steindler, M. J., "Summary Report on the Development of Annular Centrifugal Contactors", ANL-82-21.

13. Herbst, R. S., et al., "TRUEX Partitioning Studies Applied to ICPP Sodium-Bearing Waste", WINCO-1206, May 1994.

14. Vandegrift, G. F., "Development And Demonstration of the TRUEX Solvent Extraction Process", Proceedings of WM Symposia, February 28 - March 4, 1993.

15. Law, J. D., et al., "CMP Flowsheet Development for the Separation of Actinides from ICPP Sodium-Bearing Waste Using Centrifugal Contactors", INEL-95/0414, August 1995. 


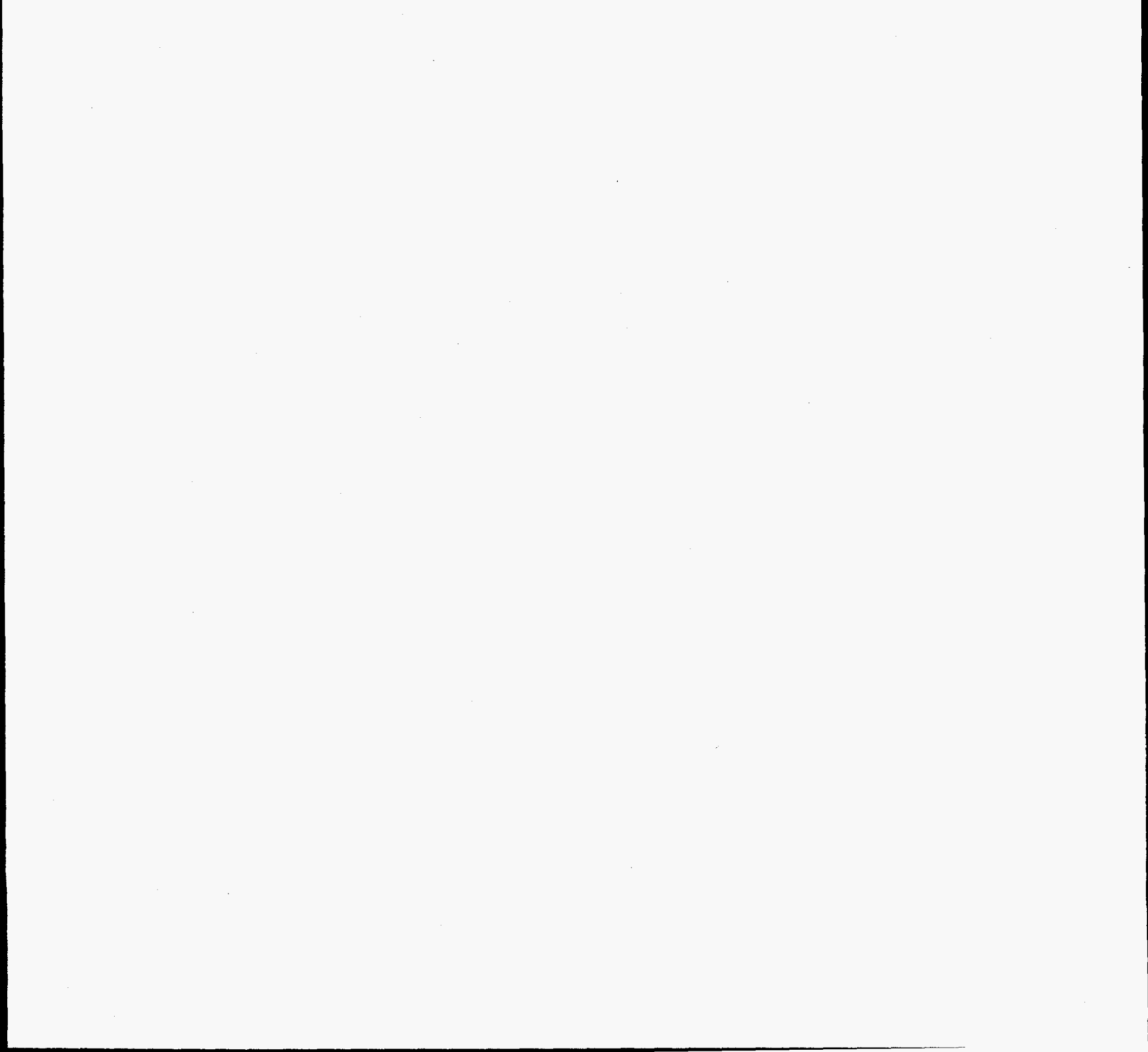


APPENDIX A:

Experimental Data 
Table A.1 Data for nitric acid extraction by the CMP solvent.

\begin{tabular}{|c|c|c|c|c|c|c|c|c|c|}
\hline \multicolumn{2}{|c|}{ Sample } & \multirow{2}{*}{$\begin{array}{l}\begin{array}{c}\text { Conc. }^{\dagger} \\
(\underline{M})\end{array} \\
0.0109\end{array}$} & $\mathrm{D}_{\mathrm{HNO} 3}$ & Conc. $^{\dagger}$ & $\mathrm{D}_{\mathrm{HNO} 3}$ & Conc. $^{\dagger}$ & $\mathrm{D}_{\mathrm{HNO} 3}$ & Conc. $^{\dagger}$ & $\mathrm{D}_{\mathrm{HNO} 3}$ \\
\hline Ext. \#1 & Aq. & & \multirow{2}{*}{0.348} & 0.408 & \multirow{2}{*}{0.372} & 0.0124 & \multirow{2}{*}{0.185} & 0.416 & \multirow{2}{*}{0.345} \\
\hline & Org. & 0.00379 & & 0.152 & & 0.0022 & & 0.143 & \\
\hline \multirow[t]{2}{*}{ Ext. \#2 } & Aq. & 0.0133 & \multirow{2}{*}{0.391} & 0.498 & \multirow{2}{*}{0.427} & 0.0127 & \multirow{2}{*}{0.336} & 0.495 & \multirow{2}{*}{0.419} \\
\hline & Org. & 0.0052 & & 0.213 & & 0.0043 & & 0.207 & \\
\hline \multirow[t]{2}{*}{ Ext. \#3 } & Aq. & 0.0146 & \multirow{2}{*}{0.363} & 0.531 & \multirow{2}{*}{0.454} & 0.0147 & \multirow{2}{*}{0.290} & 0.552 & \multirow{2}{*}{0.289} \\
\hline & Org. & 0.0053 & & 0.241 & & 0.0043 & & 0.215 & \\
\hline \multirow[t]{2}{*}{ Ext. \#4 } & Aq. & 0.0341 & \multirow{2}{*}{0.531} & 0.532 & \multirow{2}{*}{0.496} & 0.02 & \multirow{2}{*}{$1.710^{\dagger}$} & 0.522 & \multirow{2}{*}{0.456} \\
\hline & Org. & 0.0181 & & 0.264 & & 0.034 & & 0.252 & \\
\hline \multirow[t]{2}{*}{ Ext. \#1 } & Aq. & 0.6897 & \multirow{2}{*}{0.462} & 2.132 & \multirow{2}{*}{0.393} & 0.701 & \multirow{2}{*}{0.438} & 2.159 & \multirow{2}{*}{0.376} \\
\hline & Org. & 0.3186 & & 0.838 & & 0.307 & & 0.812 & \\
\hline \multirow[t]{2}{*}{ Ext. \#2 } & Aq. & 0.898 & \multirow{2}{*}{0.478} & 2.74 & \multirow{2}{*}{$0.864^{\dagger}$} & 0.903 & \multirow{2}{*}{0.457} & 2.789 & \multirow{2}{*}{0.356} \\
\hline & Org. & 0.429 & & 2.37 & & 0.412 & & 0.993 & \\
\hline \multirow[t]{2}{*}{ Ext. \#3 } & Aq. & 0.966 & & 2.96 & & 0.974 & & 3.005 & \\
\hline & Org. & 0.469 & 0.480 & 2.37 & $0.199^{\circ}$ & 0.447 & 0.459 & 0.956 & 0.318 \\
\hline Ext. \#4 & Aq. & 1.512 & & 2.429 & & 0.762 & & 2.873 & \\
\hline & Org. & 0.682 & 0.431 & 0.976 & 0.402 & 0.454 & 0.590 & 1.155 & 0.402 \\
\hline Ext. \#1 & Aq. & 3.628 & & 6.360 & & 3.598 & & 6.120 & \\
\hline & Org. & 1.230 & 0.339 & 1.691 & 0.266 & 1.263 & 0.351 & 1.928 & 0.315 \\
\hline Ext. $\# 2$ & Aq. & 4.628 & & 7.761 & & 4.653 & & 7.867 & \\
\hline & Org. & 1.467 & 0.311 & 1.987 & 0.256 & 1.466 & 0.315 & 2.108 & 0.286 \\
\hline Ext. \#3 & Aq. & 4.804 & & 7.818 & & 4.846 & & 8.158 & \\
\hline & Org. & 1.523 & 0.317 & 2.228 & 0.285 & 1.483 & 0.306 & 1.999 & 0.245 \\
\hline Ext. \#4 & Aq. & 5.331 & & 8.465 & & 4.768 & & 7.970 & \\
\hline & Org. & 1.589 & 98 & 2.413 & 0.285 & 1.798 & 0.377 & 2.056 & 0.258 \\
\hline
\end{tabular}

${ }^{\dagger}$ Data appears erroneous compared to other points and therefore not used. 
Table A.2 Americium, mercury, and plutonium data with varying nitric acid concentrations.

\begin{tabular}{|c|c|c|c|c|c|c|c|}
\hline \multicolumn{4}{|c|}{ Am-241 (Carbonate Washed DHDECMP) } & \multicolumn{4}{|c|}{ Am-241 (Unwashed DHDECMP) } \\
\hline $\begin{array}{c}\mathrm{HNO}_{3} \\
\text { Conc. } \\
(\underline{\mathrm{M}})\end{array}$ & $\begin{array}{c}\text { Phase } \\
\text { Analysis } \\
(\mathrm{dpm} / \mathrm{mL})\end{array}$ & $\begin{array}{c}\text { Distribution } \\
\text { Coefficient } \\
\text { D }\end{array}$ & $\begin{array}{c}\text { Material } \\
\text { Balance } \\
(\%)\end{array}$ & $\begin{array}{l}\mathrm{HNO}_{3} \\
\text { Conc. } \\
(\underline{\mathrm{M}})\end{array}$ & $\begin{array}{c}\text { Phase } \\
\text { Analysis } \\
(\mathrm{dpm} / \mathrm{mL})\end{array}$ & $\begin{array}{c}\text { Distribution } \\
\text { Coefficient } \\
\text { D }\end{array}$ & $\begin{array}{c}\text { Material } \\
\text { Balance } \\
(\%)\end{array}$ \\
\hline 0.02 & $\begin{array}{lr}\text { Org.: } & 537 \\
\text { Aq.: } & 142962\end{array}$ & 0.001 & 100 & 0.03 & $\begin{array}{lr}\text { Org.: } & 1518 \\
\text { Aq..: } & 142704\end{array}$ & 0.011 & 99.58 \\
\hline 0.55 & $\begin{array}{ll}\text { Org.: } & 66296 \\
\text { Aq.: } & 77909\end{array}$ & 0.851 & 100 & 0.53 & $\begin{array}{ll}\text { Org.: } & 65742 \\
\text { Aq.: } & 78196\end{array}$ & 0.841 & 100.4 \\
\hline 0.76 & $\begin{array}{ll}\text { Org.: } & 96239 \\
\text { Aq.: } & 50018\end{array}$ & 1.92 & 99.4 & 1.51 & $\begin{array}{lr}\text { Org.: } & 113521 \\
\text { Aq.: } & 36329\end{array}$ & 3.12 & 96.99 \\
\hline 2.87 & $\begin{array}{lr}\text { Org.: } & 130367 \\
\text { Aq.: } & 16657\end{array}$ & 7.83 & 99.5 & 2.43 & $\begin{array}{lr}\text { Org.: } & 125502 \\
\text { Aq.: } & 21770\end{array}$ & 5.76 & 99.28 \\
\hline 4.77 & \begin{tabular}{|lr} 
Org.: & 135488 \\
Aq.: & 10399
\end{tabular} & 13.0 & 100 & 5.33 & \begin{tabular}{|rr} 
Org.: & 137110 \\
Aq.: & 11028
\end{tabular} & 12.4 & 98.68 \\
\hline 7.82 & $\begin{array}{lr}\text { Org.: } & 137162 \\
\text { Aq.: } & 9781\end{array}$ & 14.0 & 99.7 & 8.46 & 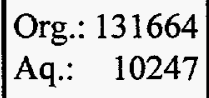 & 12.8 & 103.2 \\
\hline \multicolumn{4}{|c|}{$\mathrm{Pu}-238$} & \multicolumn{4}{|c|}{$\mathrm{Hg}-203$} \\
\hline 0.01 & $\begin{array}{lr}\text { Org.: } & 1427 \\
\text { Aq.: } & 15805\end{array}$ & 0.090 & 101 & 0.11 & $\begin{array}{lr}\text { Org.: } & 65608 \\
\text { Aq.: } & 4996\end{array}$ & 13.1 & 103.7 \\
\hline 0.05 & $\begin{array}{ll}\text { Org.: } & 11556 \\
\text { Aq.: } & 28010\end{array}$ & 0.413 & 103 & 0.44 & $\begin{array}{lr}\text { Org.: } & 58212 \\
\text { Aq.: } & 1890\end{array}$ & 30.8 & 107.9 \\
\hline 0.51 & $\begin{array}{ll}\text { Org.: } & 30882 \\
\text { Aq.: } & 10085\end{array}$ & 3.06 & 99.5 & 1.02 & $\begin{array}{lr}\text { Org.: } & 70159 \\
\text { Aq.: } & 2925\end{array}$ & 24.0 & 100.5 \\
\hline 2.87 & $\begin{array}{lr}\text { Org.: } & 36982 \\
\text { Aq.: } & 4236\end{array}$ & 8.73 & 99.2 & 2.62 & $\begin{array}{lr}\text { Org.: } & 65058 \\
\text { Aq.: } & 9200\end{array}$ & 7.07 & 100.2 \\
\hline 4.95 & $\begin{array}{lr}\text { Org.: } & 39024 \\
\text { Aq.: } & 2601\end{array}$ & 15.0 & 99.8 & 5.18 & $\begin{array}{|ll|}\text { Org.: } & 42738 \\
\text { Aq.: } & 27651\end{array}$ & 1.55 & 106.4 \\
\hline 7.23 & \begin{tabular}{|rr} 
Org.: & 40260 \\
Aq.: & 1609
\end{tabular} & 25.0 & 98.6 & 8.32 & $\begin{array}{ll}\text { Org.: } & 19712 \\
\text { Aq.: } & 56817\end{array}$ & 0.347 & 101.4 \\
\hline
\end{tabular}


Table A.3 Data from zirconium-95 tracer tests with simulated SBW.

\begin{tabular}{|c|c|c|c|c|c|c|c|}
\hline \multirow{3}{*}{$\begin{array}{c}\text { Contact } \\
\text { Extraction } 1\end{array}$} & \multicolumn{3}{|c|}{ Test \#1 } & \multicolumn{4}{|c|}{ Test \#2 } \\
\hline & \multirow{2}{*}{\begin{tabular}{|c|}
$\begin{array}{c}\text { Phase } \\
\text { Analysis } \\
\text { (dpm/mL) }\end{array}$ \\
Feed: 226.7 \\
Org.: $\quad$ BDL \\
Aq.: 233.0
\end{tabular}} & \multirow{2}{*}{$\begin{array}{c}\begin{array}{c}\text { Distribution } \\
\text { Coefficient } \\
\left(\mathrm{D}_{\mathrm{zr}}\right)\end{array} \\
\ldots\end{array}$} & \multirow{2}{*}{$\begin{array}{c}\begin{array}{c}\text { Material } \\
\text { Balance } \\
(\%)\end{array} \\
97.3\end{array}$} & \multicolumn{2}{|c|}{$\begin{array}{c}\text { Phase } \\
\text { Analysis } \\
\text { (dpm/mL) }\end{array}$} & \multirow{2}{*}{$\begin{array}{c}\begin{array}{c}\text { Distribution } \\
\text { Coefficient } \\
\left(\mathrm{D}_{2 \mathrm{r}}\right)\end{array} \\
0.975\end{array}$} & \multirow{2}{*}{$\begin{array}{r}\begin{array}{c}\text { Materia } \\
\text { Balance } \\
(\%)\end{array} \\
98.3\end{array}$} \\
\hline & & & & $\begin{array}{l}\text { Feed } \\
\text { Org. } \\
\text { Aq.: }\end{array}$ & $\begin{array}{l}373.3 \\
187.5 \\
192.4\end{array}$ & & \\
\hline Extraction 2 & $\begin{array}{ll}\text { Feed: } & 226.7 \\
\text { Org.: } & 1.25 \\
\text { Aq.: } & 219.0\end{array}$ & 0.006 & 103 & $\begin{array}{l}\text { Feed } \\
\text { Org. } \\
\text { Aq.: }\end{array}$ & $\begin{array}{l}560.8 \\
291.7 \\
276.6\end{array}$ & 1.05 & 98.7 \\
\hline Extraction 3 & $\begin{array}{|ll|}\text { Feed: } & 227.95 \\
\text { Org.: } & 53.48 \\
\text { Aq.: } & 175.2 \\
\end{array}$ & 0.305 & 99.7 & $\begin{array}{l}\text { Feed } \\
\text { Org. } \\
\text { Aq.: }\end{array}$ & \begin{tabular}{r|}
665.0 \\
349.3 \\
316
\end{tabular} & 1.11 & 100 \\
\hline Solution: & & $3.0 \underline{\mathrm{M}} \mathrm{HNO}_{3}$ & & & $0 \underline{\mathrm{M}} \mathrm{HI}$ & $\mathrm{O}_{3}$ in $0.1 \underline{\mathrm{M}} \mathrm{I}$ & (strip) \\
\hline Scrub 1 & $\begin{array}{|lr|}\text { Org.: } & 28.4 \\
\text { Aq.: } & 25.91 \\
\end{array}$ & 1.10 & 98.5 & & \begin{tabular}{r|}
0.93 \\
331.8
\end{tabular} & 0.003 & 105 \\
\hline Scrub 2 & $\begin{array}{lr}\text { Org.: } & 26.01 \\
\text { Aq.: } & 1.93\end{array}$ & 13.5 & 102 & & $\begin{array}{l}0.53 \\
0.75\end{array}$ & 0.707 & 73.0 \\
\hline Scrub 3 & $\begin{array}{lr}\text { Org.: } & 23.24 \\
\text { Aq.: } & 1.41\end{array}$ & 16.5 & 106 & $\begin{array}{l}\text { Org. } \\
\text { Aq.: }\end{array}$ & $\begin{array}{l}0.60 \\
0.58\end{array}$ & 1.03 & 44.9 \\
\hline Solution: & & $5.0 \underline{\mathrm{M}} \mathrm{HNO}_{3}$ & & & $\underline{M} \mathrm{HN}$ & $\mathrm{O}_{3}$ in $0.04 \underline{\mathrm{M}}$ & A (strip) \\
\hline Scrub 1 & $\begin{array}{|ll|}\text { Org.: } & 34.59 \\
\text { Aq.: } & 18.72 \\
\end{array}$ & 1.85 & 100 & & & 1.02 & 54.1 \\
\hline Scrub 2 & $\begin{array}{lr}\text { Org.: } & 34.85 \\
\text { Aq.: } & 2.10 \\
\end{array}$ & 16.6 & 93.6 & $\begin{array}{l}\text { Org. } \\
\text { Aq.: }\end{array}$ & $\begin{array}{l}0.53 \\
0.57\end{array}$ & 0.930 & 51.0 \\
\hline Scrub 3 & $\begin{array}{|rr|}\text { Org.: } & 34.1 \\
\text { Aq.: } & 0.978\end{array}$ & 34.9 & 99.4 & $\begin{array}{l}\text { Org. } \\
\text { Aq.: }\end{array}$ & $\begin{array}{l}0.48 \\
0.08\end{array}$ & 6.00 & 94.6 \\
\hline Solution & & $8.0 \mathrm{M} \mathrm{HNO}_{3}$ & & & & & \\
\hline Scrub 1 & $\begin{array}{|rr|}\text { Org.: } & 46.43 \\
\text { Aq.: } & 5.45 \\
\end{array}$ & 8.52 & 103 & & & NP & \\
\hline Scrub 2 & $\begin{array}{lr}\text { Org.: } & 44.77 \\
\text { Aq.: } & \text { BDL }\end{array}$ & -- & 104 & & & & \\
\hline Scrub 3 & $\begin{array}{lr}\text { Org.: } & 45.57 \\
\text { Aq.: } & \text { BDL }\end{array}$ & $\cdots$ & 98.2 & & & & \\
\hline
\end{tabular}


Table A.3 (Cont.) Data from zirconium-95 tracer tests with simulated SBW.

\begin{tabular}{|c|c|c|c|c|c|c|}
\hline \multicolumn{7}{|c|}{$\overline{\text { Test \#3 }}$} \\
\hline Contact & \multicolumn{2}{|c|}{ Phase Analysis (dpm/mL) } & \multicolumn{2}{|c|}{ Distribution Coefficient $\left(\mathrm{D}_{\mathrm{zr}}\right)$} & \multicolumn{2}{|c|}{ Material Balance (\%) } \\
\hline Extraction 1 & $\begin{array}{l}\text { Feed: } \\
\text { Org.: } \\
\text { Aq.: }\end{array}$ & $\begin{array}{l}383.8 \\
184.8 \\
200.3\end{array}$ & \multicolumn{2}{|c|}{0.922} & \multicolumn{2}{|c|}{99.7} \\
\hline Extraction 2 & $\begin{array}{l}\text { Feed: } \\
\text { Org.: } \\
\text { Aq.: }\end{array}$ & $\begin{array}{l}568.6 \\
285.8 \\
289.2\end{array}$ & \multicolumn{2}{|c|}{0.988} & \multicolumn{2}{|c|}{98.9} \\
\hline Extraction 3 & $\begin{array}{l}\text { Feed: } \\
\text { Org.: } \\
\text { Aq.: }\end{array}$ & $\begin{array}{l}669.6 \\
330.4 \\
333.9\end{array}$ & \multicolumn{2}{|c|}{0.990} & \multicolumn{2}{|c|}{101} \\
\hline Solution: & \multicolumn{3}{|c|}{$0.04 \underline{\mathrm{M}} \mathrm{HEDPA}$ in $0.04 \underline{\mathrm{M}} \mathrm{HNO}_{3}$} & \multicolumn{3}{|c|}{$0.05 \mathrm{M} \mathrm{H}_{2} \mathrm{C}_{2} \mathrm{O}_{4}$ in $0.01 \mathrm{MHNO}$} \\
\hline & $\begin{array}{c}\text { Phase } \\
\text { Analysis } \\
\text { (dpm/mL) }\end{array}$ & $\begin{array}{c}\text { Distribution } \\
\text { Coefficient } \\
\left(D_{\mathrm{zr}}\right)\end{array}$ & $\begin{array}{c}\text { Material } \\
\text { Balance } \\
(\%)\end{array}$ & $\begin{array}{c}\text { Phase } \\
\text { Analysis } \\
(\mathrm{dpm} / \mathrm{mL})\end{array}$ & $\begin{array}{c}\text { Distribution } \\
\text { Coefficient } \\
\left(\mathrm{D}_{\mathrm{Zn}_{\mathrm{r}}}\right)\end{array}$ & $\begin{array}{c}\text { Material } \\
\text { Balance } \\
(\%)\end{array}$ \\
\hline Strip 1 & $\begin{array}{|lr|}\text { Org.: } & \text { BDL } \\
\text { Aq.: } & 328.2 \\
\end{array}$ & $\sim 0$ & 100.7 & $\begin{array}{|lr|}\text { Org.: } & \text { BDL } \\
\text { Aq.: } & 335.0 \\
\end{array}$ & $\sim 0$ & 98.6 \\
\hline Strip 2 & $\begin{array}{ll}\text { Org.: } & \text { BDL } \\
\text { Aq.: } & \text { BDL }\end{array}$ & ND & ND & \begin{tabular}{ll|} 
Org.: & BDL \\
Aq.: & BDL
\end{tabular} & ND & ND \\
\hline Strip 3 & $\begin{array}{ll}\text { Org.: } & \text { BDL } \\
\text { Aq.: } & \text { BDL }\end{array}$ & ND & ND & $\begin{array}{|ll|}\text { Org.: } & \text { BDL } \\
\text { Aq.: } & \text { BDL } \\
\end{array}$ & ND & ND \\
\hline
\end{tabular}

BDL: Below Detection Limit

ND: Not Determined 
Table A.4 Data from mercury-203 tracer tests with simulated SBW.

\begin{tabular}{|c|c|c|c|c|c|c|c|}
\hline \multirow[b]{2}{*}{ Contact } & \multicolumn{3}{|c|}{ Test \#1 } & \multicolumn{4}{|c|}{ Test \#2 } \\
\hline & $\begin{array}{c}\text { Phase } \\
\text { Analysis } \\
(\mathrm{dpm} / \mathrm{mL})\end{array}$ & $\begin{array}{c}\text { Distribution } \\
\text { Coefficient } \\
\left(D_{\mathrm{Hg}}\right) \\
\end{array}$ & $\begin{array}{c}\text { Material } \\
\text { Balance } \\
(\%)\end{array}$ & Contact & $\begin{array}{c}\text { Phase } \\
\text { Analysis } \\
(\mathrm{dpm} / \mathrm{mL})\end{array}$ & $\begin{array}{c}\text { Distribution } \\
\text { Coefficient } \\
\left(D_{\mathrm{Hg}}\right)\end{array}$ & $\begin{array}{c}\text { Material } \\
\text { Balance } \\
(\%)\end{array}$ \\
\hline Extraction 1 & $\begin{array}{lr}\text { Feed: } & 134.1 \\
\text { Org.: } & 124.2 \\
\text { Aq.: } & 4.73\end{array}$ & 26.3 & 104 & Extraction 1 & $\begin{array}{lr}\text { Feed: } & 163.8 \\
\text { Org.: } & 141.5 \\
\text { Aq.: } & 18.5 \\
\end{array}$ & 7.65 & 102 \\
\hline Extraction 2 & $\begin{array}{l}\text { Feed: } 258.3 \\
\text { Org.: } 241.0 \\
\text { Aq.: } 18.63\end{array}$ & 12.9 & 99.5 & Extraction 2 & $\begin{array}{ll}\text { Feed: } & 305.3 \\
\text { Org.: } & 273.6 \\
\text { Aq.: } & 29.71\end{array}$ & 9.21 & 101 \\
\hline Extraction 3 & \begin{tabular}{ll|} 
Feed: 375.1 \\
Org.: 342.1 \\
Aq.: 34.67 \\
\end{tabular} & 9.90 & 99.6 & Extraction 3 & $\begin{array}{ll}\text { Feed: } & 437.4 \\
\text { Org.: } & 408.6 \\
\text { Aq.: } & 43.75 \\
\end{array}$ & 9.34 & 96.7 \\
\hline Solution: & \multicolumn{3}{|c|}{$3 \underline{\mathrm{M} \mathrm{HNO}_{3}}$} & \multicolumn{4}{|c|}{$0.04 \underline{\mathrm{M}} \mathrm{HEDPA}$ in $0.04 \underline{\mathrm{M}} \mathrm{HNO}_{3}$} \\
\hline Strip 1 & $\begin{array}{ll}\text { Org.: } & 301.8 \\
\text { Aq.: } & 41.04\end{array}$ & 7.35 & 99.8 & Strip 1 & $\begin{array}{lr}\text { Org.: } & 419.5 \\
\text { Aq.: } & 8.06\end{array}$ & 52.0 & 95.6 \\
\hline Strip 2 & $\begin{array}{ll}\text { Org.: } & 264.1 \\
\text { Aq.: } & 38.17\end{array}$ & 6.92 & 99.8 & Strip 2 & $\begin{array}{lr}\text { Org.: } & 423.1 \\
\text { Aq.: } & 4.37\end{array}$ & 96.8 & 98.1 \\
\hline Strip 3 & $\begin{array}{ll}\text { Org.: } & 222.4 \\
\text { Aq.: } & 33.77\end{array}$ & 6.59 & 103 & Strip 3 & $\begin{array}{lr}\text { Org.: } & 422 \\
\text { Aq.: } & 3.08\end{array}$ & 137 & 99.5 \\
\hline Solution: & \multicolumn{3}{|c|}{$5 \underline{\mathrm{M}} \mathrm{HNO}_{3}$} & Strip 4 & $\begin{array}{lr}\text { Org.: } & 401.3 \\
\text { Aq.: } & 1.93\end{array}$ & 208 & 105 \\
\hline Strip 1 & $\begin{array}{ll}\text { Org.: } & 227.9 \\
\text { Aq.: } & 104.6\end{array}$ & 2.18 & 103 & Solution: & \multicolumn{3}{|c|}{$0.25 \underline{\mathrm{M} \mathrm{Na}} \mathrm{CO}_{3}$} \\
\hline Strip 2 & $\begin{array}{ll}\text { Org.: } & 146.3 \\
\text { Aq.: } & 82.34\end{array}$ & 1.78 & 99.7 & Wash 1 & $\begin{array}{ll}\text { Org.: } & 181.5 \\
\text { Aq.: } & 218.9\end{array}$ & 0.829 & 100 \\
\hline Strip 3 & $\begin{array}{ll}\text { Org.: } & 99.54 \\
\text { Aq.: } & 52.41\end{array}$ & 1.9 & 96.3 & Wash 2 & $\begin{array}{lc}\text { Org.: } & 176.4 \\
\text { Aq.: } & \text { BDL }\end{array}$ & --- & 103 \\
\hline Solution: & & $8 \underline{\mathrm{M} H \mathrm{HO}_{3}}$ & & \multirow{4}{*}{\multicolumn{4}{|c|}{ NP }} \\
\hline Strip 1 & $\left|\begin{array}{ll}\text { Org.: } & 127.5 \\
\text { Aq.: } & 207.2\end{array}\right|$ & 0.615 & 102 & & & & \\
\hline Strip 2 & $\begin{array}{ll}\text { Org.: } & 44.92 \\
\text { Aq.: } & 78.92\end{array}$ & 0.544 & 103 & & & & \\
\hline Strip 3 & $\begin{array}{ll}\text { Org.: } & 22.10 \\
\text { Aq.: } & 22.19\end{array}$ & 0.999 & 101 & & & & \\
\hline
\end{tabular}


Table A.5 Data from the americium-241 tracer tests with simulated SBW.

\begin{tabular}{|c|c|c|c|c|c|c|c|c|c|}
\hline \multirow[b]{2}{*}{ Contact } & \multirow{2}{*}{\multicolumn{2}{|c|}{$\begin{array}{c}\text { Phase } \\
\text { Analysis } \\
(\mathrm{dpm} / \mathrm{ml})\end{array}$}} & $\mathrm{D}_{\mathrm{Am}}$ & \multirow{2}{*}{\multicolumn{2}{|c|}{$\begin{array}{l}\text { Phase } \\
\text { Analysis } \\
(\mathrm{dpm} / \mathrm{ml})\end{array}$}} & $\mathrm{D}_{\mathrm{Am}}$ & \multirow{2}{*}{\multicolumn{2}{|c|}{$\begin{array}{l}\text { Phase } \\
\text { Analysis } \\
(\mathrm{dpm} / \mathrm{ml})\end{array}$}} & $\mathrm{D}_{\mathrm{Am}}$ \\
\hline & & & $\% \mathrm{MB}$ & & & $\% \mathrm{MB}$ & & & $\% \mathrm{MB}$ \\
\hline \multirow{2}{*}{ Extraction 1} & \multirow{2}{*}{$\begin{array}{l}\text { Feed: } \\
\text { Org.: } \\
\text { Aq.: }\end{array}$} & \multirow{2}{*}{$\begin{array}{r}1628 \\
1624 \\
72.04\end{array}$} & 22.54 & \multirow{2}{*}{$\begin{array}{l}\text { Feed: } \\
\text { Org.: } \\
\text { Aq.: }\end{array}$} & \multirow{2}{*}{$\begin{array}{r}2747 \\
2662 \\
113.8\end{array}$} & 23.39 & \multirow{2}{*}{$\begin{array}{l}\text { Feed: } \\
\text { Org.: } \\
\text { Aq.: }\end{array}$} & \multirow{2}{*}{$\begin{array}{r}170637 \\
167387 \\
7244\end{array}$} & 23.11 \\
\hline & & & 95.99 & & & 98.96 & & & 97.71 \\
\hline \multirow{2}{*}{ Extraction 2} & \multirow{2}{*}{$\begin{array}{l}\text { Feed: } \\
\text { Org.: } \\
\text { Aq.: }\end{array}$} & \multirow{2}{*}{$\begin{array}{r}3252 \\
3145 \\
144.5\end{array}$} & 21.76 & \multirow{2}{*}{$\begin{array}{l}\text { Feed: } \\
\text { Org.: } \\
\text { Aq.: }\end{array}$} & \multirow{2}{*}{$\begin{array}{r}5409 \\
5254 \\
224.6\end{array}$} & 23.39 & \multirow{2}{*}{\multicolumn{2}{|c|}{$\begin{array}{lr}\text { Feed: } & 338024 \\
\text { Org.: } & 321508 \\
\text { Aq.: } & 13992 \\
\end{array}$}} & 22.98 \\
\hline & & & 98.86 & & & 98.73 & & & 100.8 \\
\hline \multirow{2}{*}{ Extraction 3} & \multirow{2}{*}{\multicolumn{2}{|c|}{$\begin{array}{lr}\text { Feed: } & 4773 \\
\text { Org.: } & 4747 \\
\text { Aq.: } & 202.4\end{array}$}} & 23.45 & \multirow{2}{*}{$\begin{array}{l}\text { Feed: } \\
\text { Org.: } \\
\text { Aq.: }\end{array}$} & \multirow{2}{*}{$\begin{array}{r}8001 \\
7531 \\
327.9\end{array}$} & 22.97 & \multirow{2}{*}{$\begin{array}{l}\text { Feed: } \\
\text { Org.: } \\
\text { Aq.: }\end{array}$} & \multirow{2}{*}{$\begin{array}{r}508661 \\
473297 \\
20855\end{array}$} & 22.69 \\
\hline & & & 96.44 & & & 101.8 & & & 102.9 \\
\hline Solution: & \multicolumn{3}{|c|}{$0.04 \underline{\mathrm{M}} \mathrm{HNO}_{3}$ in $0.04 \underline{\mathrm{MHEDPA}}$} & \multicolumn{3}{|c|}{ 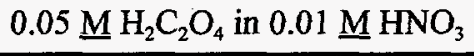 } & \multicolumn{3}{|c|}{$0.05 \underline{\mathrm{M}} \mathrm{HAN}$ in $0.015 \mathrm{M} \mathrm{HNO}_{3}$} \\
\hline \multirow[t]{2}{*}{ Strip 1} & \multirow{2}{*}{$\begin{array}{l}\text { Org.: } \\
\text { Aq.: }\end{array}$} & \multirow{2}{*}{$\begin{array}{l}1054 \\
3454\end{array}$} & 0.305 & \multirow{2}{*}{$\begin{array}{l}\text { Org.: } \\
\text { Aq.: }\end{array}$} & \multirow{2}{*}{$\begin{array}{l}4543 \\
3222\end{array}$} & 1.41 & \multirow{2}{*}{\multicolumn{2}{|c|}{$\begin{array}{ll}\text { Org.: } & 12968 \\
\text { Aq.: } & 60394\end{array}$}} & 0.215 \\
\hline & & & 105.3 & & & 96.99 & & & 99.80 \\
\hline \multirow[t]{2}{*}{ Strip 2} & \multirow{2}{*}{$\begin{array}{l}\text { Org.: } \\
\text { Aq.: }\end{array}$} & 10.42 & 0.010 & Org.: & 643.8 & 0.167 & Org.: & 1857 & 0.166 \\
\hline & & 1044 & 99.96 & Aq. & 3845 & 101.2 & Aq. & 1214 & 99.21 \\
\hline Strip 3 & Org.: & BDL & ND & Org.: & 3.06 & 0.0066 & Org.: & 1094 & 1.52 \\
\hline & & 7.69 & ND & & .1 & 136.9 & & 721 & 102.3 \\
\hline Solution: & & $0.25 \underline{\mathrm{M}}$ & $\mathrm{CO}_{3}$ & & & & & $0.25 \underline{M}$ & $\overline{\mathrm{CO}_{3}}$ \\
\hline Wash 1 & Org.: & $\mathrm{BDL}$ & ND & & & & Org.: & 583 & 1.44 \\
\hline & $\mathrm{Aq}$ & BDL & ND & & $\mathrm{N}$ & & $\mathrm{Ac}$ & 405 & 110.7 \\
\hline Wash 2 & Org.: & BDL & ND & & & & Org.: & 519 & 2.07 \\
\hline $0.2 \mathrm{J1} 1 \mathrm{Na}_{2} \mathrm{U}_{3}$ & & BDL & ND & & & & Aq. & & 75.7 \\
\hline
\end{tabular}


Table A.6 Data from the plutonium tracer tests with simulated SBW.

\begin{tabular}{|c|c|c|c|c|c|c|c|c|}
\hline Isotope: & \multicolumn{2}{|c|}{ Pu-239 } & \multicolumn{2}{|c|}{$\mathrm{Pu}-238$} & \multicolumn{2}{|c|}{ Pu-239 } & \multicolumn{2}{|c|}{ Pu-239 (Hg Free Sim) } \\
\hline \multirow[t]{2}{*}{ Stage } & \multirow{2}{*}{$\begin{array}{c}\text { Phase } \\
\text { Analysis } \\
(\mathrm{dpm} / \mathrm{ml})\end{array}$} & $\mathrm{D}_{\mathrm{Pu}}$ & \multirow{2}{*}{$\begin{array}{l}\text { Phase } \\
\text { Analysis } \\
(\mathrm{dpm} / \mathrm{ml})\end{array}$} & $\mathrm{D}_{\mathrm{Pu}}$ & \multirow{2}{*}{$\begin{array}{c}\text { Phase } \\
\text { Analysis } \\
(\mathrm{dpm} / \mathrm{ml})\end{array}$} & $\mathrm{D}_{\mathrm{Pu}}$ & \multirow{2}{*}{$\begin{array}{l}\text { Phase } \\
\text { Analysis } \\
(\mathrm{dpm} / \mathrm{ml})\end{array}$} & $\mathrm{D}_{\mathrm{Pu}}$ \\
\hline & & $\% \mathrm{MB}$ & & $\% \mathrm{MB}$ & & $\% \mathrm{MB}$ & & $\% \mathrm{MB}$ \\
\hline \multirow{2}{*}{ Extraction 1} & \multirow{2}{*}{$\begin{array}{lr}\text { Feed: } & 118372 \\
\text { Org.: } & 118165 \\
\text { Aq.: } & 249\end{array}$} & 475 & \multirow{2}{*}{$\begin{array}{lr}\text { Feed: } & 103193 \\
\text { Org.: } & 98803 \\
\text { Aq.: } & 1029\end{array}$} & 96.02 & \multirow{2}{*}{$\begin{array}{lr}\text { Feed: } & 119561 \\
\text { Org.: } & 121541 \\
\text { Aq.: } & 150\end{array}$} & 810.3 & \multirow{2}{*}{$\begin{array}{lr}\text { Feed: } & 118354 \\
\text { Org.: } & 117923 \\
\text { Aq. } & 115\end{array}$} & 1025 \\
\hline & & 99.97 & & 103.4 & & 98.20 & & 100.3 \\
\hline \multirow{2}{*}{ Extraction 2} & \multirow{2}{*}{$\begin{array}{l}\text { Feed: } 236537 \\
\text { Org.: } 239652\end{array}$} & 884 & \multirow{2}{*}{$\begin{array}{lr}\text { Feed: } & 201996 \\
\text { Org.: } & 197434 \\
\text { Aq.: } & 1679\end{array}$} & 117.6 & \multirow{2}{*}{$\begin{array}{lr}\text { Feed: } & 119561 \\
\text { Org.: } & 239231 \\
\text { Aq.: } & 208\end{array}$} & 1150 & $\begin{array}{l}\text { Feed: } 118354 \\
\text { Org.: } 239352\end{array}$ & 1425 \\
\hline & & 98.59 & & 101.4 & & 100.7 & $\begin{array}{lr}\text { Aqg.: } & 168352\end{array}$ & 98.60 \\
\hline \multirow{2}{*}{ Extraction 3} & $\begin{array}{l}\text { Feed: } 354910 \\
\text { Org.: } 360077\end{array}$ & 1143 & $\begin{array}{l}\text { Feed: } 300628 \\
\text { Org.: } 297343\end{array}$ & 123.2 & $\begin{array}{l}\text { Feed: } 119561 \\
\text { Org.: } 360319\end{array}$ & 1315 & $\begin{array}{l}\text { Feed: } 118354 \\
\text { Org.: } 365513\end{array}$ & 1486 \\
\hline & Aq.: $\quad 315$ & 98.48 & Aq.: $\quad 2413$ & 100.3 & Aq.: $\quad 274$ & 99.50 & Aq.: $\quad 246$ & 97.8 \\
\hline Solution: & \multicolumn{2}{|c|}{$0.015 \underline{\mathrm{M} H \mathrm{HO}_{3}}$} & \multicolumn{2}{|c|}{$\begin{array}{c}0.04 \underline{\mathrm{M}} \mathrm{HEDPA} \text { in } \\
0.04 \mathrm{MHNO}_{3}\end{array}$} & \multicolumn{2}{|c|}{$0.01 \mathrm{M} \mathrm{HNO}_{3}$} & \multicolumn{2}{|c|}{$\begin{array}{c}0.05 \underline{\mathrm{M} \mathrm{H}} \mathrm{C}_{2} \mathrm{O}_{4} \text { in } \\
0.005 \underline{\mathrm{M}} \mathrm{HNO}_{3}\end{array}$} \\
\hline \multirow[t]{2}{*}{ Strip 1} & \multirow{2}{*}{$\begin{array}{lr}\text { Org.: } & 368689 \\
\text { Aq.: } & 2653\end{array}$} & 139 & \multirow{2}{*}{$\begin{array}{lr}\text { Org:: } & 3466 \\
\text { Aq.: } & 294518\end{array}$} & 0.012 & \multirow{2}{*}{$\begin{array}{lr}\text { Org:: } & 366609 \\
\text { Aq.: } & 2355\end{array}$} & 15.5 & \multirow{2}{*}{$\begin{array}{l}\text { Org:: } 70040 \\
\text { Aq.: } 277690\end{array}$} & 0.252 \\
\hline & & 95.13 & & 99.78 & & 97.70 & & 105.1 \\
\hline \multirow[t]{2}{*}{ Strip 2} & \multirow{2}{*}{$\begin{array}{lr}\text { Org.: } & 364947 \\
\text { Aq.: } & 8565\end{array}$} & 42.6 & Org.: & 0.018 & Org.: 367643 & 56.2 & Org.: $\quad 1389$ & 0.025 \\
\hline & & 98.71 & 3464 & 98.25 & 539 & 98.00 & 55594 & 122.9 \\
\hline Strip 3 & Org.: 352485 & 23.5 & Org.: & 4.56 & Org.: 356543 & 40.6 & Org.: & 0.24 \\
\hline & Aq.: $\quad 15021$ & 99.30 & 8.34 & 135.6 & 8791 & 100.6 & 929 & 120.4 \\
\hline Strip 4 & Org.: 347184 & 58.8 & Org.: & $\mathrm{BDL}$ & & & & \\
\hline & Aq.: & 103.4 & $A d$ & & & & & \\
\hline Strip 5 & $\mathrm{~N}$ & & Org.: & 43.4 & & & & \\
\hline & & & Aq. & 84.64 & & & & \\
\hline
\end{tabular}


Table A.7 Data from the uranium-233 tracer tests with simulated SBW.

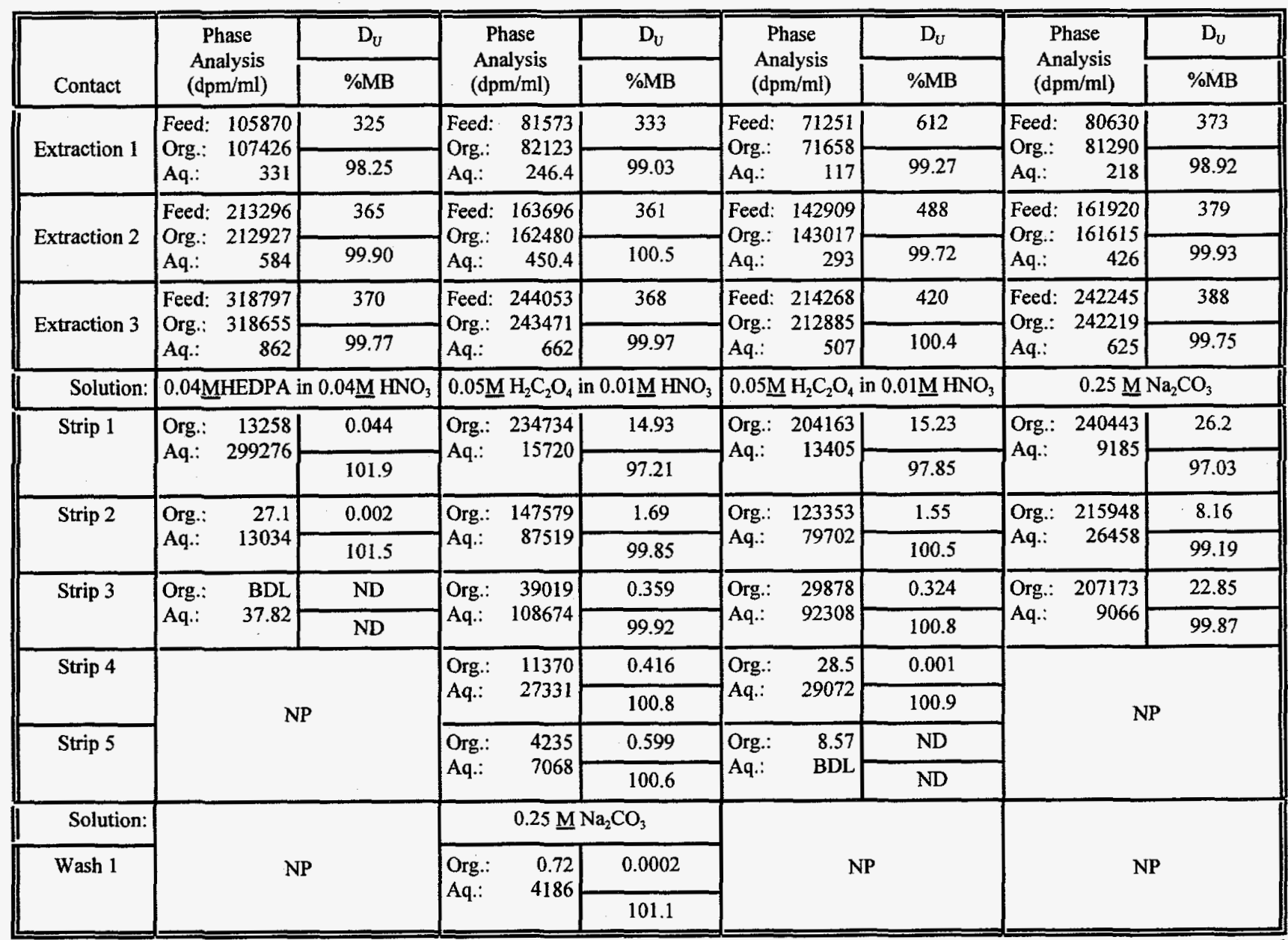


Table A.8 Data from the neptunium-239 tracer tests with simulated SBW.

\begin{tabular}{|c|c|c|c|c|c|c|c|c|c|}
\hline \multirow[b]{2}{*}{ Contact } & \multirow{2}{*}{\multicolumn{2}{|c|}{$\begin{array}{l}\text { Phase } \\
\text { Analysis } \\
(\mathrm{dpm} / \mathrm{ml})\end{array}$}} & $D_{N p}$ & \multirow{2}{*}{\multicolumn{2}{|c|}{$\begin{array}{c}\text { Phase } \\
\text { Analysis } \\
(\mathrm{dpm} / \mathrm{ml})\end{array}$}} & Material & \multirow{2}{*}{\multicolumn{2}{|c|}{$\begin{array}{c}\text { Phase } \\
\text { Analysis } \\
(\mathrm{dpm} / \mathrm{ml})\end{array}$}} & Material \\
\hline & & & $\% \mathrm{MB}$ & & & $\% \mathrm{MB}$ & & & $\% \mathrm{MB}$ \\
\hline \multirow{2}{*}{ Extraction 1} & \multirow{2}{*}{$\begin{array}{l}\text { Feed: } \\
\text { Org.: } \\
\text { Aq.: }\end{array}$} & \multirow{2}{*}{$\begin{array}{l}87.57 \\
64.48 \\
25.31\end{array}$} & 2.55 & \multirow{2}{*}{$\begin{array}{l}\text { Feed: } \\
\text { Org.: } \\
\text { Aq.: }\end{array}$} & \multirow{2}{*}{$\begin{array}{l}87.57 \\
64.48 \\
25.31\end{array}$} & 2.55 & \multirow{2}{*}{$\begin{array}{l}\text { Feed: } \\
\text { Org.: } \\
\text { Aq.: }\end{array}$} & \multirow{2}{*}{$\begin{array}{l}87.57 \\
64.48 \\
25.31\end{array}$} & 2.55 \\
\hline & & & 97.53 & & & 97.53 & & & 97.53 \\
\hline \multirow{2}{*}{ Extraction 2} & \multirow{2}{*}{$\begin{array}{l}\text { Feed: } \\
\text { Org.: } \\
\text { Aq.: }\end{array}$} & \multirow{2}{*}{$\begin{array}{l}152.1 \\
122.5 \\
29.44\end{array}$} & 4.16 & \multirow{2}{*}{$\begin{array}{l}\text { Feed: } \\
\text { Org.: } \\
\text { Aq.: }\end{array}$} & \multirow{2}{*}{$\begin{array}{l}152.1 \\
122.5 \\
29.44\end{array}$} & 4.16 & \multirow{2}{*}{$\begin{array}{l}\text { Feed: } \\
\text { Org.: } \\
\text { Aq.: }\end{array}$} & \multirow{2}{*}{$\begin{array}{l}152.1 \\
122.5 \\
29.44\end{array}$} & 4.16 \\
\hline & & & 100.1 & & & 100.1 & & & 100.1 \\
\hline \multirow{2}{*}{ Extraction 3} & \multirow{2}{*}{$\begin{array}{l}\text { Feed: } \\
\text { Org.: } \\
\text { Aq.: }\end{array}$} & \multirow{2}{*}{$\begin{array}{l}210.1 \\
187.6 \\
32.24\end{array}$} & 5.82 & \multirow{2}{*}{$\begin{array}{l}\text { Feed: } \\
\text { Org.: } \\
\text { Aq.: }\end{array}$} & \multirow{2}{*}{$\begin{array}{l}210.1 \\
187.6 \\
32.24\end{array}$} & 5.82 & \multirow{2}{*}{$\begin{array}{l}\text { Feed: } \\
\text { Org.: } \\
\text { Aq.: }\end{array}$} & \multirow{2}{*}{$\begin{array}{l}210.1 \\
187.6 \\
32.24\end{array}$} & 5.82 \\
\hline & & & 95.57 & & & 95.57 & & & 95.57 \\
\hline Solution: & \multicolumn{3}{|c|}{$0.04 \underline{\mathrm{MHEDPA}}$ in $0.04 \underline{\mathrm{M}} \mathrm{HNO}_{3}$} & \multicolumn{3}{|c|}{ 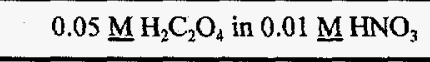 } & \multicolumn{3}{|c|}{$0.05 \underline{\mathrm{M} N a} \mathrm{CO}_{3}$} \\
\hline \multirow[t]{2}{*}{ Strip 1} & \multirow{2}{*}{$\begin{array}{l}\text { Org.: } \\
\text { Aq.: }\end{array}$} & \multirow{2}{*}{$\begin{array}{r}2.72 \\
187.8\end{array}$} & 0.014 & \multirow{2}{*}{$\begin{array}{l}\text { Org.: } \\
\text { Aq.: }\end{array}$} & \multirow{2}{*}{$\begin{array}{l}28.78 \\
162.7\end{array}$} & 0.177 & \multirow{2}{*}{$\begin{array}{l}\text { Org.: } \\
\text { Aq.: }\end{array}$} & \multirow{2}{*}{$\begin{array}{l}115.9 \\
82.76\end{array}$} & 1.40 \\
\hline & & & 98.47 & & & 97.97 & & & 94,43 \\
\hline \multirow[t]{2}{*}{ Strip 2} & \multirow{2}{*}{$\begin{array}{l}\text { Org.: } \\
\text { Aq.: }\end{array}$} & 1.85 & 0.56 & Org:: & 2.36 & 0.089 & Org.: & 75.63 & 2.19 \\
\hline & & & 52.51 & & & 99.86 & & & 105.2 \\
\hline Strip 3 & Org.: & 1.79 & 0.81 & Org.: & 3.23 & 1.88 & Org.: & 47.16 & 6.04 \\
\hline & & & 46.25 & & & 47.67 & & & 137.6 \\
\hline
\end{tabular}


Table A.9 Data from the technetium-99m tracer tests with simulated SBW.

\begin{tabular}{|c|c|c|c|c|c|c|c|c|}
\hline \multirow[t]{2}{*}{ Contact } & \multirow{2}{*}{$\begin{array}{c}\text { Phase } \\
\text { Analysis } \\
(\mathrm{dpm} / \mathrm{ml})\end{array}$} & $\mathrm{D}_{\mathrm{T} c}$ & \multirow{2}{*}{$\begin{array}{c}\text { Phase } \\
\text { Analysis } \\
(\mathrm{dpm} / \mathrm{ml})\end{array}$} & $\mathrm{D}_{\mathrm{Tc}}$ & \multirow{2}{*}{$\begin{array}{c}\text { Phase } \\
\text { Analysis } \\
(\mathrm{dpm} / \mathrm{ml})\end{array}$} & $\mathrm{D}_{\mathrm{Tc}}$ & \multirow{2}{*}{$\begin{array}{c}\text { Phase } \\
\text { Analysis } \\
(\mathrm{dpm} / \mathrm{ml})\end{array}$} & $\mathrm{D}_{\mathrm{Tc}}$ \\
\hline & & $\% \mathrm{MB}$ & & $\% \mathrm{MB}$ & & $\% \mathrm{MB}$ & & $\% \mathrm{MB}$ \\
\hline \multirow{2}{*}{ Extraction 1} & \multirow{2}{*}{$\begin{array}{ll}\text { Feed: } & 6386 \\
\text { Org.: } & 3647 \\
\text { Aq.: } & 2834\end{array}$} & 1.29 & \multirow{2}{*}{$\begin{array}{ll}\text { Feed: } & 6386 \\
\text { Org.: } & 3647 \\
\text { Aq.: } & 2834\end{array}$} & 1.29 & \multirow{2}{*}{$\begin{array}{l}\text { Feed: } \\
\text { Org.: } \\
\text { Aq.: }\end{array}$} & 1.29 & \multirow{2}{*}{$\begin{array}{l}\text { Feed: } \\
\text { Org.: } \\
\text { Aq.: }\end{array}$} & 1.29 \\
\hline & & 98.54 & & 98.54 & & 100.8 & & 100.8 \\
\hline \multirow{2}{*}{ Extraction 2} & \multirow{2}{*}{$\begin{array}{lr}\text { Feed: } & 10033 \\
\text { Org.: } & 5598 \\
\text { Aq.: } & 4426\end{array}$} & 1.26 & \multirow{2}{*}{$\begin{array}{lr}\text { Feed: } & 10033 \\
\text { Org.: } & 5598 \\
\text { Aq.: } & 4426\end{array}$} & 1.26 & \multirow{2}{*}{$\begin{array}{lr}\text { Feed: } & 15211 \\
\text { Org.: } & 8417 \\
\text { Aq.: } & 6776\end{array}$} & 1.26 & \multirow{2}{*}{$\begin{array}{lr}\text { Feed: } & 15211 \\
\text { Org.: } & 8417 \\
\text { Aq.: } & 6776\end{array}$} & 1.26 \\
\hline & & 100.1 & & 100.1 & & 100.1 & & 100.1 \\
\hline \multirow{2}{*}{ Extraction 3} & \multirow{2}{*}{$\begin{array}{lr}\text { Feed: } & 11984 \\
\text { Org.: } & 6664 \\
\text { Aq.: } & 5310\end{array}$} & 1.25 & \multirow{2}{*}{$\begin{array}{|lr|}\text { Feed: } & 11984 \\
\text { Org.: } & 6664 \\
\text { Aq.: } & 5310 \\
\end{array}$} & 1.25 & \multirow{2}{*}{$\begin{array}{l}\text { Feed: } \\
\text { Org.: } \\
\text { Aq.: }\end{array}$} & 1.25 & \multirow{2}{*}{$\begin{array}{lr}\text { Feed: } & 18203 \\
\text { Org.: } & 10083 \\
\text { Aq.: } & 8089\end{array}$} & 1.25 \\
\hline & & 100.1 & & 100.1 & & 100.2 & & 100.2 \\
\hline Solution: & \multicolumn{2}{|c|}{$\begin{array}{c}0.04 \underline{\mathrm{M}} \mathrm{HEDPA} \text { in } \\
0.04 \underline{\mathrm{M}} \mathrm{HNO}_{3}\end{array}$} & \multicolumn{2}{|c|}{$\begin{array}{c}0.05 \mathrm{M} \mathrm{H}_{2} \mathrm{C}_{2} \mathrm{O}_{4} \text { in } \\
0.01 \mathrm{M} \mathrm{HNO}_{3}\end{array}$} & \multicolumn{2}{|c|}{$\begin{array}{c}0.05 \underline{\mathrm{M}} \mathrm{H}_{2} \mathrm{C}_{2} \mathrm{O}_{4} \text { in } \\
0.01 \underline{\mathrm{M} H N \mathrm{HN}_{3}}\end{array}$} & \multicolumn{2}{|c|}{$5.0 \mathrm{M} \mathrm{HNO}_{3}$} \\
\hline \multirow[t]{2}{*}{ Strip 1} & \multirow{2}{*}{$\begin{array}{lr}\text { Org.: } & 6441 \\
\text { Aq.: } & 415\end{array}$} & 15.5 & \multirow{2}{*}{$\begin{array}{lr}\text { Org.: } & 6411 \\
\text { Aq.: } & 305 \\
\end{array}$} & 21.0 & \multirow{2}{*}{$\begin{array}{r}9701 \\
656\end{array}$} & 14.8 & $\begin{array}{l}\text { Org.: } \\
\text { Aq.: }\end{array}$ & 0.57 \\
\hline & & 97.21 & & 99.23 & & 97.35 & $\begin{array}{l}3654 \\
6451\end{array}$ & 99.79 \\
\hline \multirow[t]{2}{*}{ Strip 2} & \multirow{2}{*}{$\begin{array}{l}\text { Org:: } \\
\text { Aq.: }\end{array}$} & 14.1 & Org.: & 25.8 & Org.: & 19.9 & Org.: & 0.46 \\
\hline & & 95.20 & & 100.9 & 471 & 98.40 & & 99.69 \\
\hline Strip 3 & Org.: & 25.4 & Org.: & 22.9 & Org.: & 23.0 & Org.: & 0.45 \\
\hline & Aq.: & 98.89 & $A$ & 98.12 & 393 & 99.59 & 818 & 97.95 \\
\hline Solution: & & & & & $0.25 \underline{\mathrm{M}}$ & $\mathrm{CO}_{3}$ & & \\
\hline Wash 1 & $\mathbf{N}$ & & $N$ & & 5990 & 2.00 & Ty & \\
\hline & & & & & 2999 & 100.5 & & \\
\hline Wash 2 & & & & & Org.: & 2.79 & & \\
\hline & & & & & & 100.2 & & \\
\hline
\end{tabular}

NP $=$ Not Performed 
Table A.10 Data for the extraction of non-radioactive matrix components in SBW.

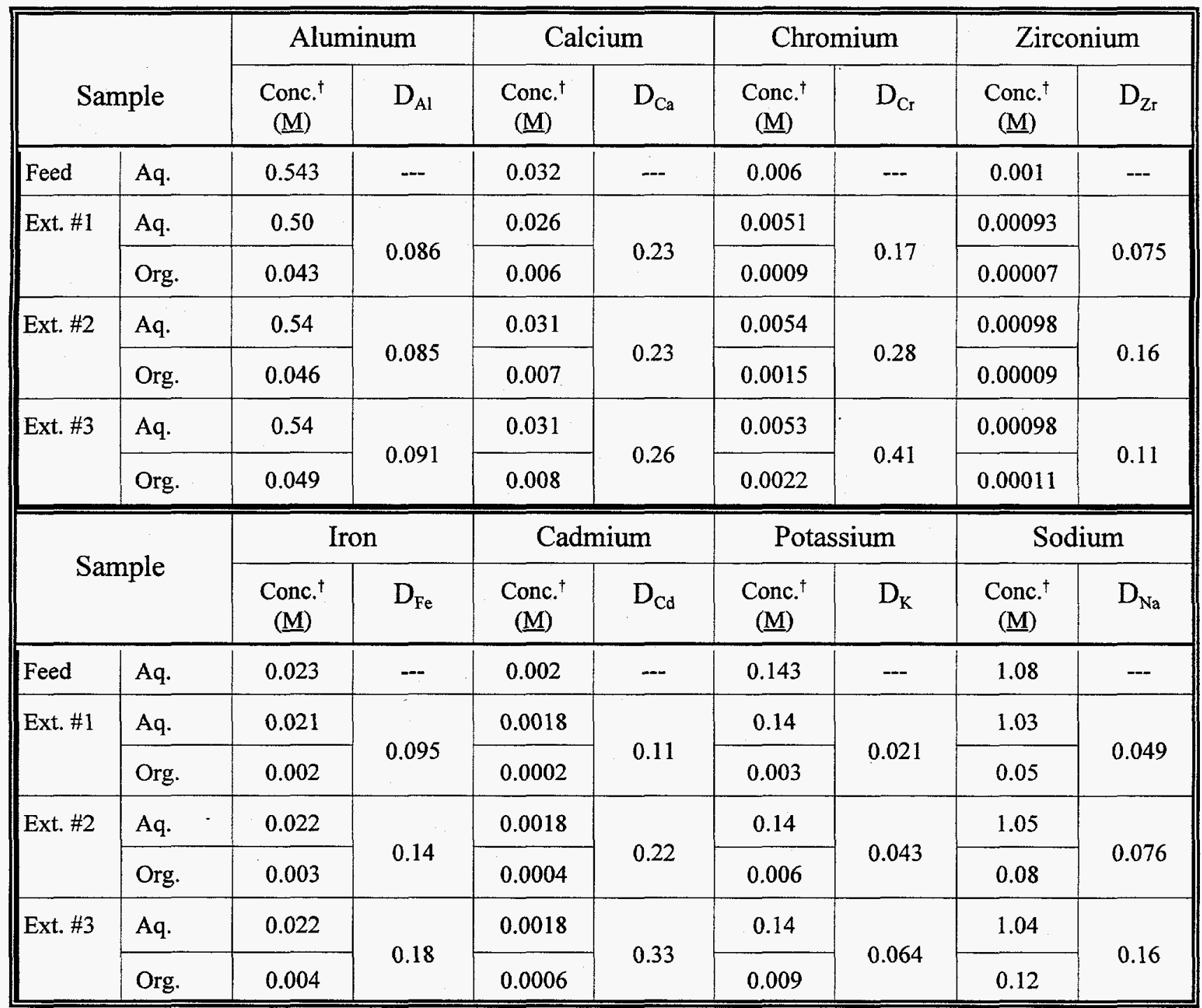

${ }^{\dagger}$ Organic phase concentrations calculated from material balance. 